\title{
Enteric glia are multipotent in culture but primarily form glia in the adult rodent gut
}

\author{
Nancy M. Joseph, ${ }^{1}$ Shenghui He, ${ }^{1}$ Elsa Quintana, ${ }^{1}$ Yun-Gi Kim, ${ }^{2}$ \\ Gabriel Núñez, ${ }^{2}$ and Sean J. Morrison ${ }^{1}$
}

\begin{abstract}
${ }^{1}$ Center for Stem Cell Biology, Howard Hughes Medical Institute, Life Sciences Institute, and Departments of Internal Medicine and Cell and Developmental Biology and ${ }^{2}$ Department of Pathology and Comprehensive Cancer Center, University of Michigan, Ann Arbor, Michigan, USA.
\end{abstract}

\begin{abstract}
It is unclear whether neurogenesis occurs in the adult mammalian enteric nervous system (ENS). Neural crestderived cells capable of forming multilineage colonies in culture, and neurons and glia upon transplantation into chick embryos, persist throughout adult life in the mammalian ENS. In this study we sought to determine the physiological function of these cells. We discovered that these cells could be identified based on CD49b expression and that they had characteristics of enteric glia, including P75, GFAP, S100B, and SOX10 expression. To test whether new neurons or glia arise in the adult gut under physiological conditions, we marked dividing progenitors with a thymidine analog in rodents under steady-state conditions, or during aging, pregnancy, dietary changes, hyperglycemia, or exercise. We also tested gut injuries including inflammation, irradiation, benzalkonium chloride treatment, partial gut stenosis, and glial ablation. We readily observed neurogenesis in a neurogenic region of the central nervous system, but not reproducibly in the adult ENS. Lineage tracing of glial cells with GFAP-Cre and GFAP-CreERT2 also detected little or no adult ENS neurogenesis. Neurogenesis in the adult gut is therefore very limited under the conditions we studied. In contrast, ENS gliogenesis was readily observed under steady-state conditions and after injury. Adult enteric glia thus have the potential to form neurons and glia in culture but are fated to form mainly glia under physiological conditions and after the injuries we studied.
\end{abstract}

\section{Introduction}

In the 1960 s Altman and Das administered tritiated thymidine to adult rats to label dividing cells and demonstrated that neurogenesis occurs in the dentate gyrus and the olfactory bulb of the CNS (1-3). Numerous other groups have since confirmed neurogenesis in the dentate gyrus and olfactory bulb of adult rodents (4-7), monkeys $(8,9)$, and humans (10). Most later studies employed the thymidine analog BrdU to label dividing cells. BrdU can be detected in cell nuclei by immunocytochemistry and can be combined with other antibodies to identify the fate of the dividing cells. Nonetheless, evidence of neurogenesis in other regions of the CNS has remained controversial due to technical issues that can sometimes falsely create the impression that $\mathrm{BrdU}^{+}$neurons are present, unless careful 3-dimensional analyses are performed by confocal microscopy (11).

Adult CNS neurons arise from multipotent stem cells that reside within the subventricular zone adjacent to the lateral ventricle as well as in the subgranular layer of the dentate gyrus $(6,12-15)$. Neurogenesis in the olfactory bulb can be stimulated by odorant enrichment $(16,17)$, while dentate gyrus neurogenesis is stimulated by exercise (18) and injury (19-21) and by certain hormones (22). Newly formed neurons may contribute to learning and memory or to the regeneration of neural circuits after injury (23-28).

In the adult peripheral nervous system (PNS) neurogenesis occurs from glial cells in the carotid body in response to reduced oxygen tension (29), but it has been unclear whether neurogenesis occurs in other regions of the adult PNS. The neurons and glia of the PNS arise during fetal and neonatal development from

Authorship note: Nancy M. Joseph and Shenghui He contributed equally to this work. Conflict of interest: The authors have declared that no conflict of interest exists. Citation for this article: J Clin Invest. 2011;121(9):3398-3411. doi:10.1172/JCI58186. the neural crest, a heterogeneous collection of progenitors that includes neural crest stem cells (NCSCs) (30). Neural crest cells migrate out of the neural tube in early to mid-gestation and were initially thought to terminally differentiate soon after migrating into embryonic tissues. However, we discovered that multipotent and self-renewing NCSCs persist throughout the PNS during late gestation $(31,32)$ and that cells with similar properties persist throughout adult life in the enteric nervous system (ENS) of rats (33) and mice $(34,35)$. Others also demonstrated the existence of these cells in the adult rodent ENS $(36,37)$ and in the human gut $(38,39)$. Upon transplantation into chick embryos, we found that flow cytometrically isolated (uncultured) adult enteric NCSC-like cells underwent limited migration and formed neurons and glia in the developing PNS (33). This suggested that the neurogenic capacity of these cells could not be an artifact of reprogramming in culture, as has sometimes been observed among CNS progenitors $(40,41)$. This raised possibility the that neurogenesis may occur in the adult ENS under physiological conditions.

The question of whether the adult ENS undergoes neurogenesis has been controversial. Based on counts of neuronal numbers and changes in cellular morphology, some have suggested that new neurons can form in the adult ENS after injury $(42,43)$, though the strength of the evidence has been debated (44). When direct approaches have been taken to assess the formation of new neurons using tritiated thymidine, no ENS neurogenesis was observed in rats after P21 (45). BrdU incorporation studies in adult mice also failed to detect ENS neurogenesis under steady-state conditions, though neurogenesis was detected after administration of an exogenous 5-hydroxytryptamine receptor $4\left(5-\mathrm{HT}_{4}\right)$ agonist (46). This suggests that stem/progenitor cells capable of undergoing neurogenesis exist in the adult gut but that neurogenesis does not occur under steady-state conditions, raising the question of 
what physiological role these cells have and whether they generate neurons in response to certain injuries or physiological changes.

To better characterize the identity of the adult enteric cells with properties similar to those of NCSCs, we developed the ability to prospectively isolate these cells by flow cytometry using CD49b $\left(\alpha_{2}\right.$ integrin). We found that these $\mathrm{CD} 4 \mathrm{~b}^{+}$cells expressed a number of markers that are shared by NCSCs and/or enteric glia, including p75, nestin, SOX10, GFAP, and S100B. Most GFAP ${ }^{+}$and S100B ${ }^{+}$ enteric glia were also $\mathrm{CD}_{4} \mathrm{bb}^{+}$, and the $\mathrm{CD}_{4} 9 \mathrm{~b}^{+}$cells exhibited the morphology and localization of glia throughout the myenteric plexus. Our data thus suggest that many adult enteric glia are capable of forming multilineage colonies in culture, similar to NCSC colonies. To assess the physiological function of these cells, we quantified the frequencies of new neurons and glia born during adulthood using in vivo BrdU incorporation as well as $\mathrm{GFAP}^{+}$cell lineage tracing in a wide range of conditions. We readily observed gliogenesis but did not reproducibly observe neurogenesis. Enteric glia, therefore, share many phenotypic and functional properties with NCSCs, but the primary physiological progenitor function of these cells is to engage in gliogenesis in the adult ENS.

\section{Results}

Prospective isolation of the multipotent cells in the adult gut. NCSCs can be identified based on their ability to form multilineage colonies in culture that contain peripherin ${ }^{+}$neurons, $\mathrm{GFAP}^{+}$glia, and $\alpha-\mathrm{SMA}^{+}$myofibroblasts $(32,33,47)$. To improve our ability to characterize the uncultured cells from the adult mouse gut that have properties similar to those of NCSCs, we prospectively identified these cells by screening a panel of more than 150 antibodies against cell surface antigens for their ability to enrich cells that formed multipotent neurospheres in culture. Adult mouse smooth muscle/myenteric plexus cells were dissociated, then stained with each antibody along with antibodies against CD45, TER119, and CD31 to eliminate hematopoietic and endothelial cells. After identifying antibodies that heterogeneously stained the CD45-TER119-CD31- (lineage- $\left.{ }^{-} \mathrm{Lin}^{-}\right]$) fraction of cells, we sorted into culture the $\mathrm{Lin}^{-}$cells that were positive or negative for each antibody. We found that CD49b (integrin $\alpha_{2}$ ) could be used to highly enrich adult mouse gut cells that formed multipotent neurospheres in culture.

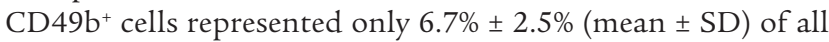
unfractionated muscle/myenteric plexus layer cells dissociated from the adult gut (Figure 1A), but included $97 \% \pm 2 \%$ of all cells that formed multipotent neurospheres (Figure 1B). Only $2.0 \% \pm 0.8 \%$ of unfractionated muscle/myenteric plexus layer cells, but $29 \% \pm 7 \%$ of all sorted CD $49 \mathrm{~b}^{+}$cells, formed neurospheres that differentiated into neurons and glia (Figure 1C). $\mathrm{CD}_{4} \mathrm{~b}^{+} \mathrm{Lin}^{-}$cells represented $4.9 \% \pm 2.3 \%$ of all unfractionated muscle/myenteric plexus cells (Figure 1D) and contained approximately $88 \%$ of all cells that formed multipotent neurospheres (Figure 1B; $97 \% \times 91 \%$ $=88 \%$ ). In addition, $44 \% \pm 6 \%$ of single $\mathrm{CD}_{4} 4 \mathrm{~b}^{+} \mathrm{Lin}^{-}$cells (sorted 1 cell/well) formed neurospheres that differentiated into neurons and glia (and often myofibroblasts as well; Figure 1, C, E, and F). The vast majority of $\mathrm{CD} 49 \mathrm{~b}^{+} \mathrm{Lin}^{-}$cells that did not form multipotent neurospheres died within the first 6-8 hours after being sorted into culture (data not shown). A small number of neurosphere-forming cells were also found in the $\mathrm{Lin}^{+}$cell fraction (Figure 1B); however, this was attributable to the formation of aggregates between $\mathrm{CD}_{49} \mathrm{~b}^{+} \mathrm{Lin}^{-}$cells and $\mathrm{Lin}^{+}$cells, and this population was excluded from subsequent analyses.
All multipotent primary neurospheres derived from $\mathrm{CD}_{4} 9 \mathrm{~b}^{+} \mathrm{Lin}^{-}$ cells were capable of generating multipotent secondary neurospheres when dissociated into single cells and replated into secondary cultures. On average, each primary neurosphere generated $668 \pm 114$ multipotent secondary neurospheres (Supplemental Figure 2A; supplemental material available online with this article; doi:10.1172/JCI58186DS1). Our data thus indicate that $\mathrm{CD}_{4} \mathrm{~b}^{+} \mathrm{Lin}^{-}$cells were highly enriched for cells that formed selfrenewing, multilineage colonies in culture and that this population contained nearly all such cells in the adult gut.

To test whether CD49b also marks multipotent cells at other developmental stages, we tested the ability of CD49b to enrich neurosphere-forming cells from E13-E15, E15-E17, or neonatal mouse gut cells. Most neurosphere-forming cells were negative for CD49b at E13-E15, but the percentage of CD49b ${ }^{+}$cells that formed multipotent neurospheres increased as development progressed, such that by P0 more than $80 \%$ of all multipotent neurospheres were formed by CD49b cells (Figure $1 G$ ).

We found that $\mathrm{CD} 49 \mathrm{~b}^{+} \mathrm{Lin}^{-}$cells uniformly expressed the glial and/or NCSC markers GFAP, S100B, SOX10, p75, and nestin, but not the neuronal marker $\mathrm{HuD}$ (Figure $1 \mathrm{H}$; note that we sometimes identified neurons using an antibody specific for $\mathrm{HuD}$ and sometimes used a different antibody that recognizes $\mathrm{HuC} / \mathrm{D})$. By flow cytometry, we also found that at least $67 \% \pm 14 \%$ of $\mathrm{Lin}^{-} \mathrm{S} 100 \mathrm{~B}^{+}$ myenteric plexus cells and $58 \% \pm 14 \%$ of $\mathrm{Lin}^{-} \mathrm{GFAP}^{+}$myenteric plexus cells stained positive for CD49b (Supplemental Figure 2B). These results demonstrate that most enteric glia express $C D 49 b$ and that

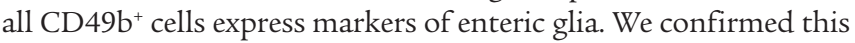
by sorting $\mathrm{CD} 49 \mathrm{~b}^{+} \mathrm{Lin}^{-}$cells from the adult myenteric plexus/muscle layer onto microscope slides, then immediately fixing and staining for GFAP. The cells appeared to uniformly stain for GFAP and to have processes reminiscent of enteric glia (Figure 1I).

To further evaluate this, we stained whole mounts of the adult myenteric plexus with antibodies against CD49b and S100B, p75, GFAP, or nestin. The specificity of these antibodies in immunofluorescence staining of whole mount gut tissues was confirmed by parallel isotype control staining of adjacent gut tissues (Supplemental Figure 1). Consistent with our flow-cytometric analysis (Figure $1 \mathrm{H}), \mathrm{CD} 49 \mathrm{~b}$ staining in the myenteric plexus strongly overlapped with S100B (Figure 1J), p75, GFAP, and nestin in a pattern consistent with enteric glia (Supplemental Figure 2, C-E). Our results suggest that many adult enteric glia have the potential to form multilineage colonies in culture.

To assess the cell cycle status of these adult $\mathrm{CD}_{4} 4 \mathrm{~b}^{+}$cells, we analyzed the DNA content of freshly isolated CD49b ${ }^{+}$Lin $^{-}$cells by propidium iodide staining. Adult gut $\mathrm{CD}_{4} 9 \mathrm{~b}^{+} \mathrm{Lin}^{-}$cells were relatively quiescent, with less than $1 \%$ of cells in $S / G_{2} / M$ phase of the cell cycle ( $>2 \mathrm{~N}$ DNA content) at any one time (Figure $1 \mathrm{~K}$ ). These results demonstrate that $\mathrm{CD}_{4} 9 \mathrm{~b}^{+}$cells represent a large subpopulation of enteric glia that are relatively quiescent in the adult gut but have the potential to proliferate extensively and to form multilineage colonies in culture. This does not necessarily mean that they actually undergo multilineage differentiation in vivo or that they include all cells with neurogenic potential in vivo. Therefore, to test whether there is neurogenesis in the adult gut, we took an approach that is unbiased with respect to cell identity, administering BrdU to adult rodents to label all dividing progenitors.

BrdU administration fails to reveal neurogenesis in the normal adult ENS. Since we found cells in the adult gut of both mice $(34,35,48)$ and rats (33) that form multilineage colonies in culture, we first tested whether 
A

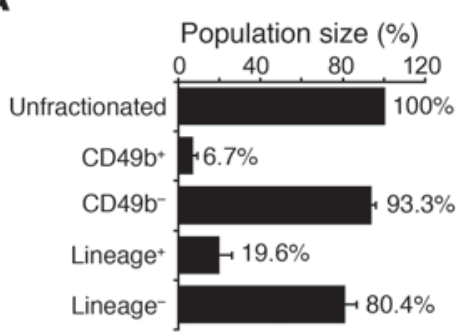

B

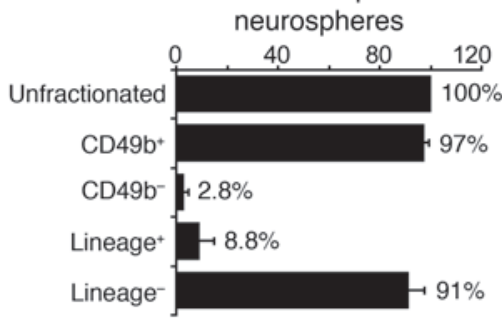

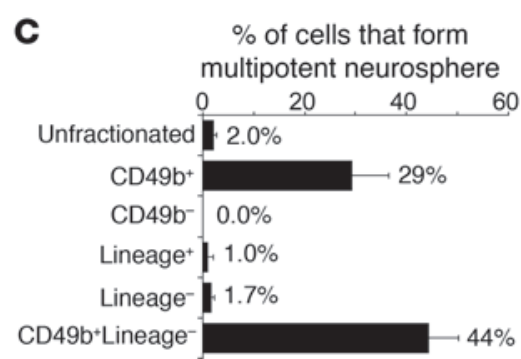
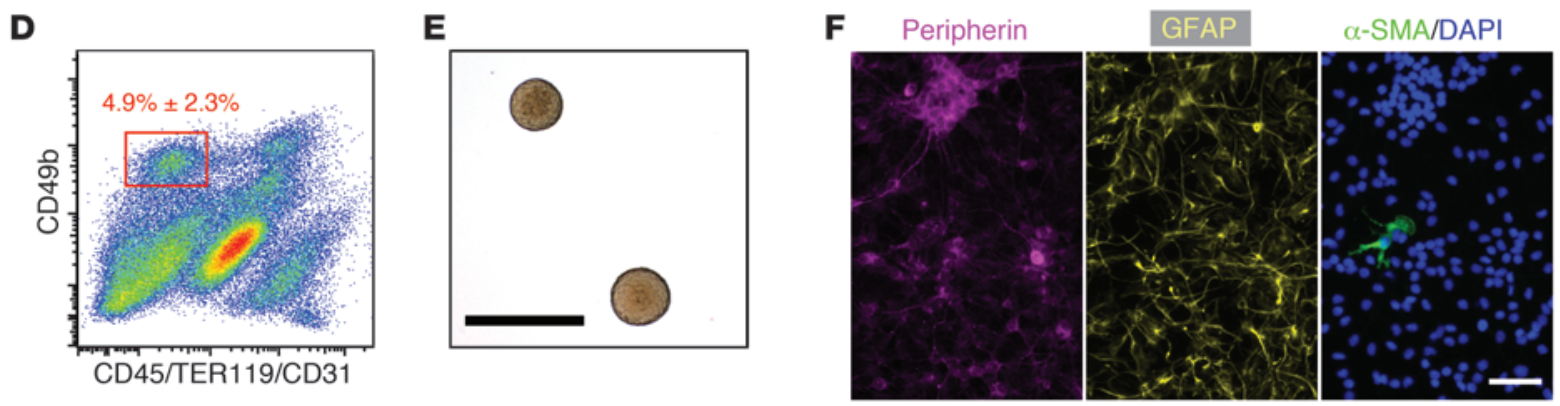

G

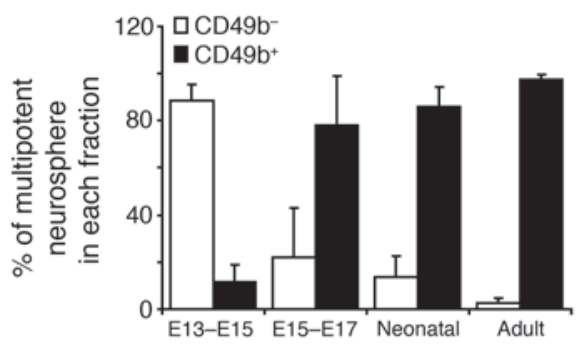

H
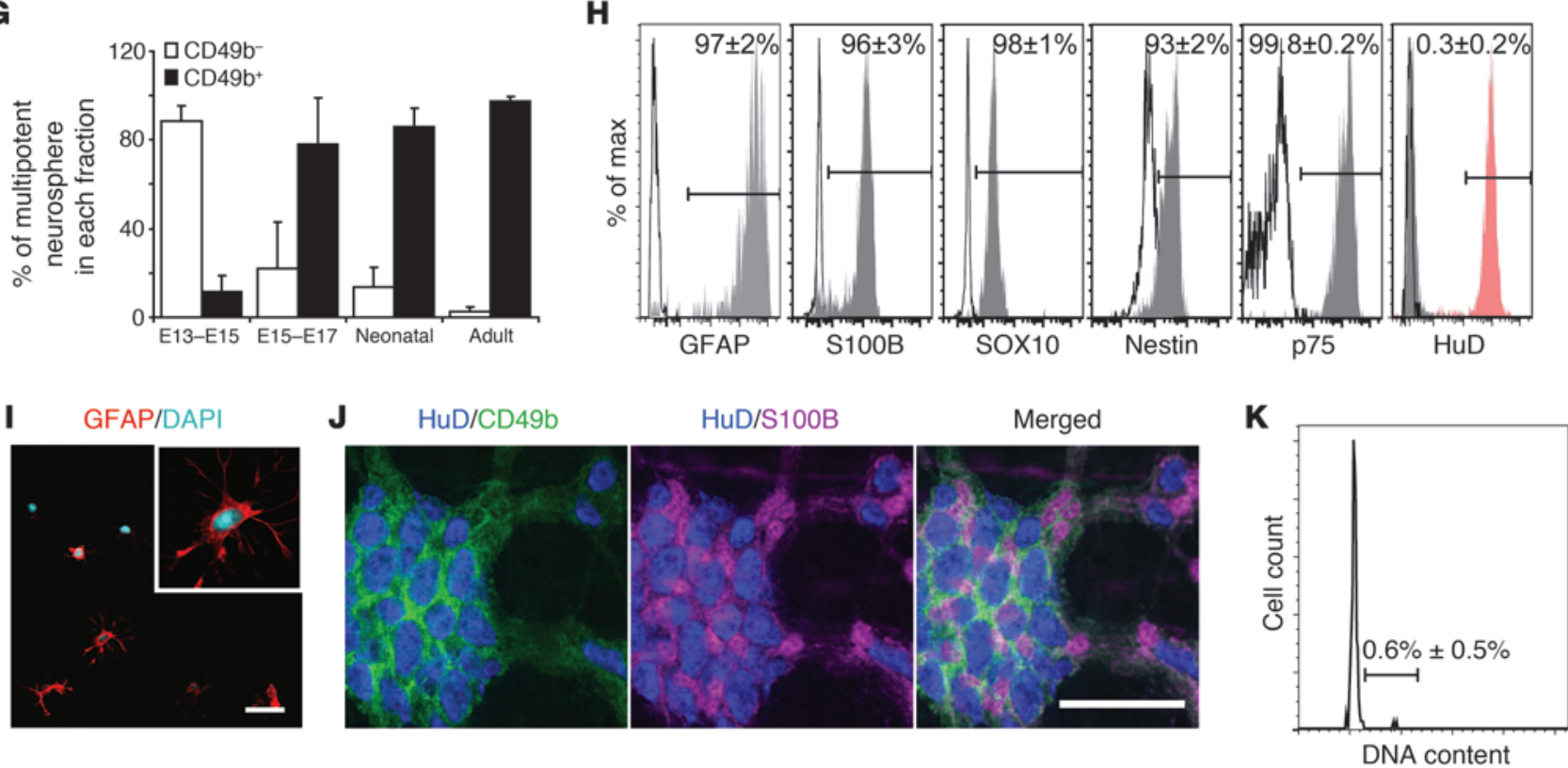

Figure 1

Adult enteric glia form multilineage colonies in culture. (A) The frequencies of dissociated adult mouse gut cells from the myenteric plexus/muscle layers that stained with antibodies against CD49b or lineage markers (CD45/TER119/CD31). (B) The percentage of all cells that formed multipotent neurospheres that were contained in each sorted cell fraction. (C) The percentage of cells in each sorted fraction that formed multipotent neurospheres in culture. (D) Flow cytometry plot of dissociated adult mouse gut cells stained with antibodies against CD49b and lineage markers. CD 49b+Lin- cells represented $4.9 \% \pm 2.3 \%$ of all unfractionated cells. (E) Primary neurospheres derived from CD49b+Lin- cells. (F) These neurospheres generated neurons (peripherin $\left.{ }^{+}\right)$, glia $\left(\mathrm{GFAP}^{+}\right)$, and myofibroblasts $\left(\alpha-\mathrm{SMA}^{+}\right)$. $(\mathbf{G})$ The percentage of all multipotent neurospheres that were formed by CD49b+ or CD49b- cells in the fetal, neonatal, and adult mouse guts. (H) Flow-cytometric analysis of fixed CD49b+Lin- cells showing that these cells (gray histograms) were nearly uniformly positive for GFAP, S100B, SOX10, nestin, and p75 (unshaded histograms are isotype control staining), but not for the neuronal marker HuD (red shaded histogram represents HuD staining of peripherin+ enteric neurons). (I) GFAP staining of freshly isolated CD49b+Lin- cells. (J) CD49b and S100B staining colocalized throughout adult myenteric ganglia, surrounding $\mathrm{HuD}^{+}$neurons, in a pattern consistent with enteric glia. (K) DNA content of CD49b+Lin- cells showing few cells in $S / G_{2} / M$ phases of the cell cycle. Scale bars: $400 \mu \mathrm{m}$ in $\mathbf{E} ; 50 \mu \mathrm{m}$ in $\mathbf{F}, \mathbf{I}$, and $\mathbf{~ J}$. All data represent mean \pm SD from 3-5 independent experiments. 


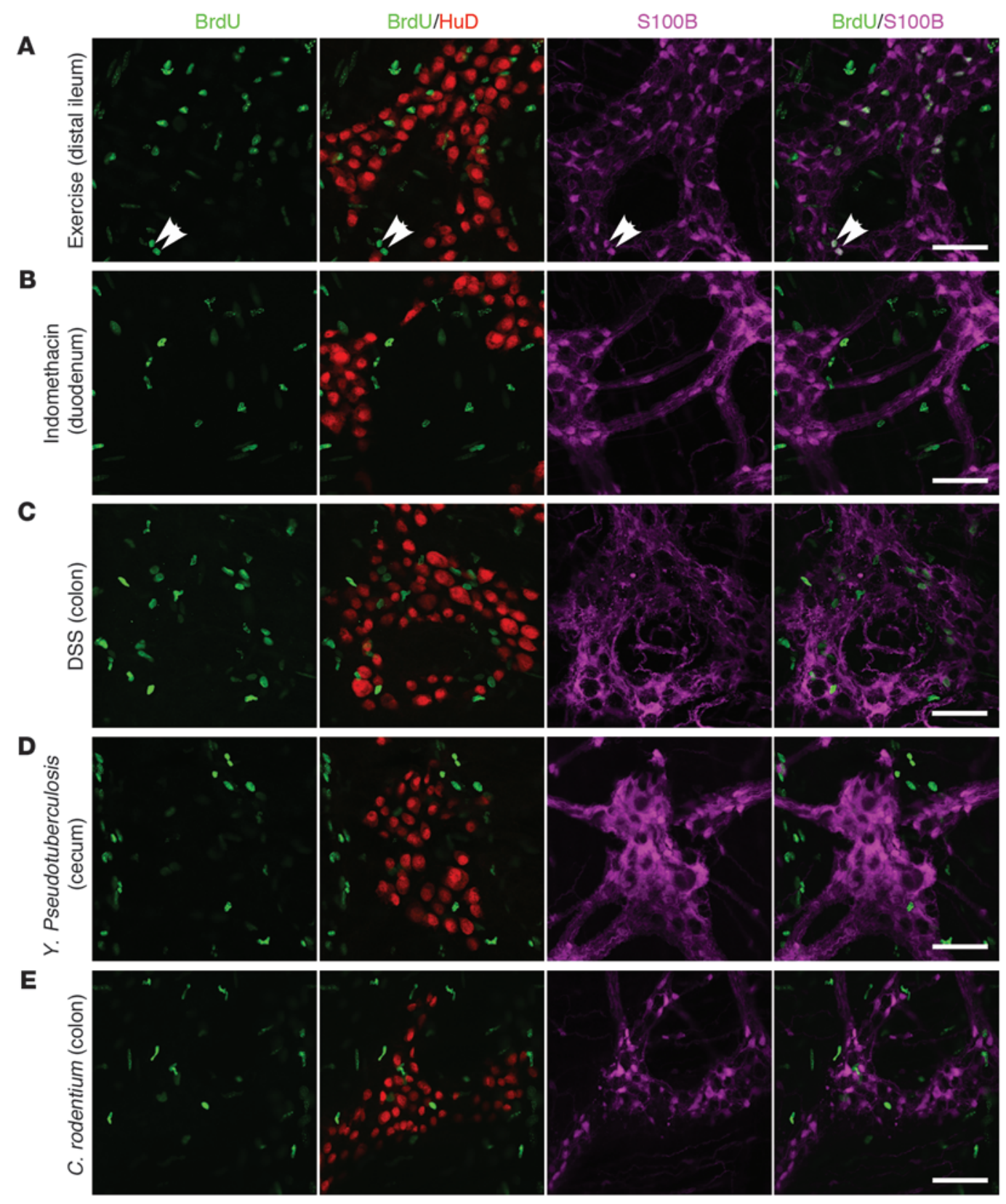

\section{Figure 2}

Voluntary exercise and gut inflammation do not promote neurogenesis in the adult ENS that is detectable by BrdU incorporation. Whole mount immunostaining of the myenteric plexus with antibodies against BrdU (green), HuD (red), and S100B (magenta) from mice that underwent voluntary exercise $(\mathbf{A})$ or mice with gut inflammation caused by administration of indomethacin (B), DSS (C), Y. pseudotuberculosis (D), or C. rodentium (E). BrdU was administered for 4 months (A) or 6 weeks (B-E), and there were 4 mice/treatment. In each treatment we analyzed the distal ileum as well as the stomach and duodenum, colon, or cecum, depending on where the gut inflammation occurred (B-E). Gliogenesis was readily observed in all mice (white arrowheads indicating $\mathrm{BrdU}^{+} \mathrm{S} 100 \mathrm{~B}^{+}$cells in $\mathbf{A}$; also Supplemental Figure 6). However, we did not observe $\mathrm{BrdU}+\mathrm{HuD}^{+}$neurons in any mice. Most $\mathrm{BrdU}^{+}$nuclei in all images were from proliferating smooth muscle progenitors and infiltrating inflammatory cells (data not shown). Scale bars: $50 \mu \mathrm{m}$.

neurogenesis could be detected in the adult rat gut under steadystate conditions. We did this by administering BrdU to rats for 2-4 weeks, followed by a chase without BrdU for 1-6 months, such that only cells that differentiated to postmitotic derivatives would retain the label at the time of analysis. BrdU was administered in the rats' drinking water beginning at P30, P45, P60, and P90. After the chase period, the rats were sacrificed, and gut tissue, along with control brain tissue, was harvested for analysis. We observed obvious neurogenesis in the dentate gyrus $\left(\mathrm{BrdU}^{+} \mathrm{NeuN}^{+}\right.$cells) of every rat analyzed (Supplemental Figure 3), consistent with prior studies $(7,18)$.

Gut sections from the same rats were stained with antibodies against BrdU and the pan-neuronal marker HuC/D. Three-dimen- 
Table 1

Failure to consistently detect adult ENS neurogenesis by BrdU incorporation in a number of physiological conditions

\begin{tabular}{|c|c|c|c|c|c|c|}
\hline $\begin{array}{l}\text { Physiological } \\
\text { condition }\end{array}$ & $\begin{array}{l}\text { Age at onset } \\
\text { of experiment }\end{array}$ & $\begin{array}{l}\text { Diet/treatment/factors } \\
\text { administered }\end{array}$ & $\begin{array}{l}\text { BrdU } \\
\text { treatment }\end{array}$ & $\begin{array}{c}\text { No. } \\
\text { animals }\end{array}$ & $\begin{array}{c}\text { Sections or } \\
\text { neurons analyzed } \\
\text { per animal }(n)\end{array}$ & $\begin{array}{c}\text { Animals with } \\
\text { neurogenesis } \\
(n)\end{array}$ \\
\hline \multicolumn{7}{|l|}{ Normal } \\
\hline & P30 & None & 2 wk pulse $+1-6$ mo chase & 6 rats & 10 sections & 0 \\
\hline & P45 & None & 2 wk pulse $+1-2$ mo chase & 3 rats & 10 sections & 0 \\
\hline & P90 & None & 4 wk pulse $+2-4$ mo chase & 2 rats & 10 sections & 0 \\
\hline & P60-P90 & None & 2 wk pulse $+1-6$ mo chase & 3 rats, 1 mouse & 10 sections & 0 \\
\hline & P120 & None & 6 wk pulse +6 wk chase & 3 mice & $>1,000$ neurons & 0 \\
\hline \multicolumn{7}{|c|}{ 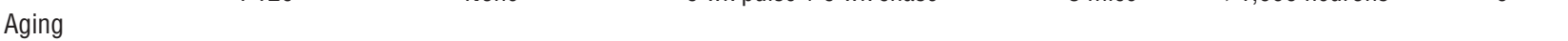 } \\
\hline & $21 \mathrm{mo}$ & None & 3 wk pulse $+2-4$ wk chase & 2 rats & 8 sections & 0 \\
\hline \multicolumn{7}{|l|}{ Pregnancy } \\
\hline & P60-90 & None & 3 wk pulse $+4-8$ wk chase & 3 rats & 8 sections & 0 \\
\hline \multicolumn{7}{|l|}{ Diabetes } \\
\hline & P90 & None & 2 wk pulse $+2-4$ wk chase & 2 rats & 8 sections & 0 \\
\hline \multicolumn{7}{|l|}{ Dietary change } \\
\hline & P30 & Normal diet & 4 wk pulse $+1-8$ mo chase & 3 rats & 8 sections & 0 \\
\hline & P30 & Liquid diet & 4 wk pulse $+1-8$ mo chase & 3 rats & 8 sections & 0 \\
\hline & P30 & High-fat diet & 4 wk pulse $+1-8$ mo chase & 3 rats & 8 sections & 0 \\
\hline & P30 & High-protein diet & 4 wk pulse $+1-8$ mo chase & 3 rats & 8 sections & 0 \\
\hline & P30 & High-carbohydrate diet & 4 wk pulse $+1-8$ mo chase & 3 rats & 8 sections & 0 \\
\hline \multicolumn{7}{|c|}{ Exercise (running wheel) } \\
\hline & P60 & On running wheel 6 mo & 4 mo pulse +2 mo chase & 4 mice & $>15,000$ neurons & 0 \\
\hline \multicolumn{7}{|l|}{ Inflammation } \\
\hline & $\mathrm{P} 60$ & DSS & 6 wk pulse +2 wk chase & 4 mice & $>15,000$ neurons & 0 \\
\hline & P60 & $\begin{array}{c}\text { Citrobacter rodentium } \\
\text { infection }\end{array}$ & 6 wk pulse +2 wk chase & 4 mice & $>15,000$ neurons & 0 \\
\hline & P60 & $\begin{array}{l}\text { Yersinia pseudotuberculosis } \\
\text { infection }\end{array}$ & 6 wk pulse +2 wk chase & 4 mice & $>15,000$ neurons & 0 \\
\hline \multicolumn{7}{|c|}{ - 5 - minotion } \\
\hline & P60-P90 & BAC; no pumps & $10-21$ d pulse $+2-44$ wk chase & 40 rats, 5 mice & 10 sections & 1 rat \\
\hline & P90 & BAC; no pumps & 10 wk pulse +3 wk chase & 4 mice & $2,000-6,000$ neurons & 0 \\
\hline & P90 & BAC; no pumps & 19 wk pulse +8 wk chase & 4 mice & $>20,000$ neurons & 0 \\
\hline & P60-P90 & BAC; vehicle & 10 d pulse $+3-6$ wk chase & 2 rats & 10 sections & 0 \\
\hline & P60-P90 & $\mathrm{BAC} ; \mathrm{EGF/FGF}$ & 10 d pulse + 3-6 wk chase & 2 rats & 10 sections & 0 \\
\hline & P60-P90 & BAC; GDNF & 10 d pulse $+3-6$ wk chase & 2 rats & 10 sections & 0 \\
\hline & P60-P90 & Saline; no pumps & $10-42$ d pulse $+3-24$ wk chase & 18 rats, 1 mouse & 10 sections & 0 \\
\hline & P90 & Saline; no pumps & 10 wk pulse +3 wk chase & 1 mouse & $>15,000$ neurons & 0 \\
\hline & P60-P90 & Saline; vehicle & 10 d pulse + 3-6 wk chase & 2 rats & 10 sections & 0 \\
\hline & P60-P90 & Saline; EGF/FGF & 10 d pulse $+3-6$ wk chase & 2 rats & 10 sections & 0 \\
\hline & P60-P90 & Saline; GDNF & 10 d pulse + 3-6 wk chase & 2 rats & 10 sections & 0 \\
\hline & P60-P90 & Gfap-tk; ganciclovir & $10-14 d$ pulse + 14-21 d chase & 7 mice & 10 sections & 0 \\
\hline & P60-P90 & WT; ganciclovir & $10-14$ d pulse + 14-21 d chase & 1 mouse & 10 sections & 0 \\
\hline & $\mathrm{P} 60$ & Irradiation & 3 wk pulse +2 wk chase & 2 mice & 6 sections & 0 \\
\hline & P60 & No irradiation control & 3 wk pulse +2 wk chase & 2 mice & 6 sections & 0 \\
\hline & P60-P90 & Partial stenosis & 2 wk pulse +2 wk chase & 2 rats & 10 sections & 0 \\
\hline
\end{tabular}

We analyzed a total of 108 rats and 51 mice that had been administered BrdU for 10 days to 4 months under a wide range of conditions. We observed $\mathrm{BrdU}+\mathrm{HuC} / \mathrm{D}^{+} \mathrm{ENS}$ neurons in only a single rat (see Supplemental Figure 7). As a positive control, we assessed dentate gyrus neurogenesis in 18 rats and readily detected $\mathrm{BrdU}^{+}$neurons in every case (Supplemental Figure 3).

sional $z$-stacks of $1-\mu \mathrm{m}$ optical sections were analyzed by confocal microscopy. Enteric neurons were identified based on several characteristics: presence within the myenteric or submucosal plexus, large nuclei with dispersed chromatin (as opposed to glia, which have small nuclei and dense chromatin), and HuC/D staining in the nucleus and cell body. Using these criteria, we found that $\mathrm{BrdU}^{+}$ nuclei were $\mathrm{HuC} / \mathrm{D}^{-}$(Supplemental Figure 4). We observed occasional examples of cells that appeared to be $\mathrm{BrdU}^{+}$and $\mathrm{HuC} / \mathrm{D}^{+}$ in a single optical section (Supplemental Figure 4A); however, after confocal analysis of all optical sections within a 5- to $10-\mu \mathrm{m}$ $z$-series, as previously described (11), all of the apparently double-labeled cells $\left(\mathrm{BrdU}+\mathrm{HuC} / \mathrm{D}^{+}\right)$were identified as being $\mathrm{BrdU}^{+} \mathrm{HuC} / \mathrm{D}^{-}$nuclei that were closely apposed to distinct BrdU-HuC/ $\mathrm{D}^{+}$neurons (probably BrdU $\mathrm{Bl}^{+}$glia adjacent to $\mathrm{HuC} / \mathrm{D}^{+}$ neurons; Supplemental Figure 4B). Despite analyzing $10 \mathrm{sec}-$ tions through the distal ileum from each of 14 rats, and detecting 

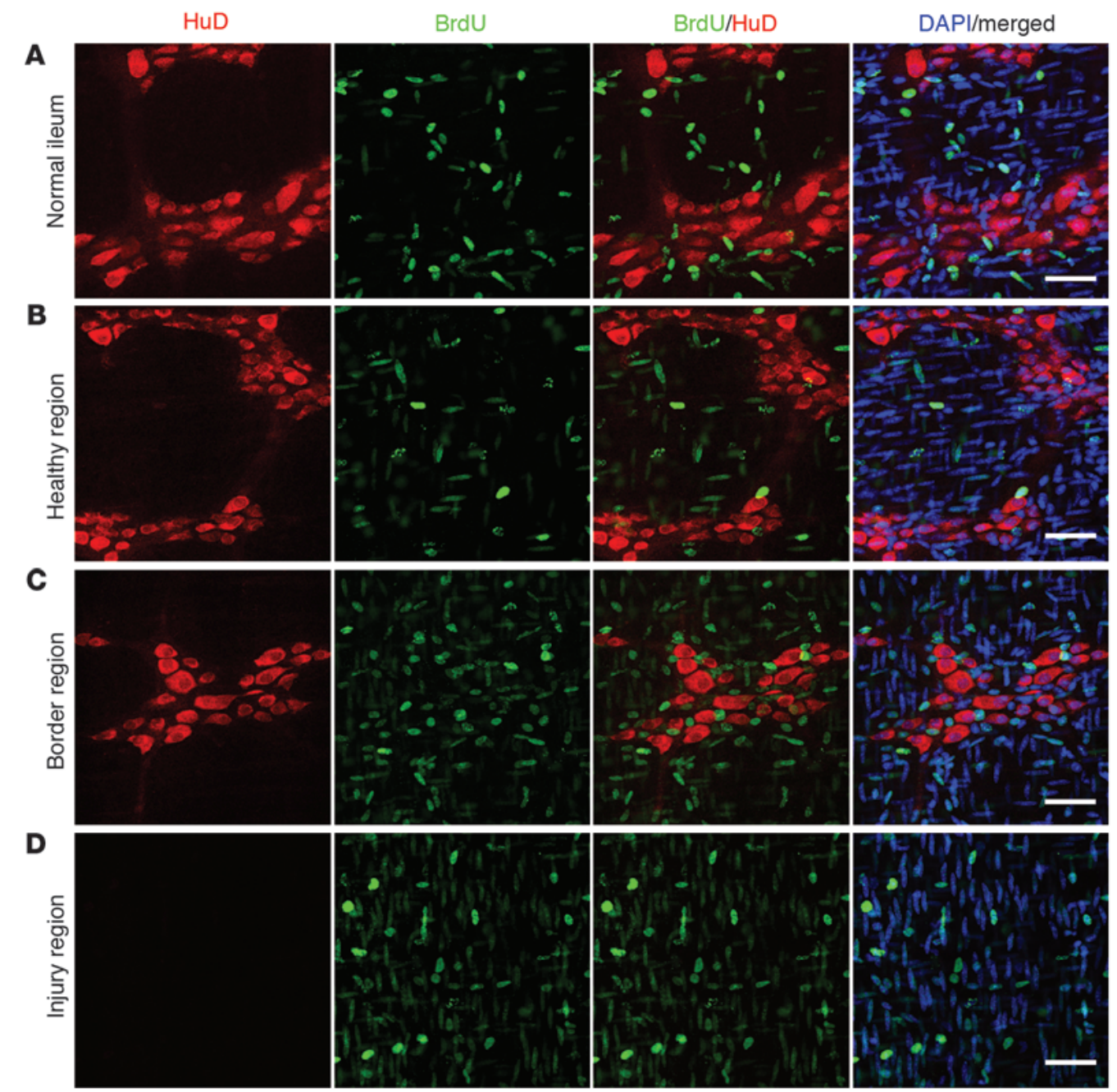

\section{Figure 3}

Focal myenteric plexus ablation by BAC treatment does not promote neurogenesis in the adult ENS that is detectable by BrdU incorporation. Whole mount staining of myenteric plexus with DAPI (blue) and antibodies against BrdU (green) and HuD (red) in mice after focal ablation of the myenteric plexus by topical BAC. These images were from mice administered BrdU for 4 months, followed by a 1-month chase without BrdU. We analyzed the distal ileum of healthy control mice (A), as well as a healthy region of the gut (B), a region that bordered the ablated region (C), and the ablated region itself (D) in mice treated with BAC. No BrdU+HuD+ cells were observed. We did not observe any neurons within the BAC-ablated region of the myenteric plexus, even 5 months after BAC treatment (D). A total of 70 rats and 15 mice were analyzed in various treatments (see Table 1 for details) that involved BrdU administration for 10 days to 19 weeks. We detected BrdU+HuD+ neurons in only a single rat (see Supplemental Figure 7). Scale bars: $50 \mu \mathrm{m}$. The elongated nuclei with more diffuse DAPI staining are from smooth muscle cells in the circular and longitudinal muscle layers surrounding the myenteric plexus.

dentate gyrus neurogenesis in the same rats, we did not observe a single convincingly $\mathrm{BrdU}+\mathrm{HuC} / \mathrm{D}^{+}$neuron in the myenteric or submucosal plexus of any of these rats (Table 1 ).

To independently assess neurogenesis in the adult mouse ENS and to test whether neurogenesis could be detected in other regions of the adult gut beyond the distal ileum, we performed a similar BrdU incorporation experiment in adult mice. We administered BrdU for 6 weeks, followed by a chase period without BrdU for 6 weeks, then analyzed the myenteric plexus in distal ileum, stomach, duodenum, cecum, and colon by whole mount immunostaining. Again, despite analyzing thousands of $\mathrm{HuD}^{+}$neurons from each gut region, we failed to observe a single $\mathrm{BrdU}^{+}$neuron in any gut region of the 3 mice examined (Supplemental Figure 5 and Table 1). These results suggest that neurogenesis does not normally occur under steady-state conditions in the adult gut or that it only occurs in a manner that does not involve cell division.

We wondered whether gut neurogenesis might be stimulated by aging, pregnancy, or hyperglycemia. To test this, we administered BrdU for 2-3 weeks, followed by a 2- to 8-week chase without BrdU, to 21 month-old rats, to pregnant rats, and to diabetic rats after streptozotocin treatment (49). Despite examining $8 \mathrm{sec}-$ tions through the distal ileum per rat in 2-3 rats per treatment, we did not observe any convincingly $\mathrm{BrdU} \mathrm{H}^{+} \mathrm{HuC} / \mathrm{D}^{+}$enteric neurons (Table 1) in the myenteric or submucosal plexus of these rats. These results suggest that aging, pregnancy, and hyperglycemia do not stimulate ENS neurogenesis or that neurogenesis occurs without cell division in these circumstances. 
To test whether dietary changes induce neurogenesis, we switched the diets of young adult rats (P30) from normal chow to liquid, high-fat, high-protein, or high-carbohydrate diet for a 3 -week period. At the time of the dietary change, BrdU was administered to the rats for 4 weeks ( 1 week beyond when the rats were switched back to their normal diet), followed by a 4- to 32-week chase without BrdU. We analyzed 8 sections through the distal ileum per rat, and 3 rats per treatment, but did not observe any convincingly BrdU ${ }^{+} \mathrm{HuC} / \mathrm{D}^{+}$neurons in the myenteric or submucosal plexus of any of these rats (Table 1 ). We also analyzed sections through the duodenum and jejunum of these animals but did not observe any $\mathrm{BrdU} \mathrm{HuC}^{+} \mathrm{\textrm {D }} \mathrm{D}^{+}$neurons in these locations either.

Since voluntary exercise promotes neurogenesis in the mouse dentate gyrus (18), we tested whether it also stimulates neurogenesis in the gut. To do this we placed a running wheel in the cages of adult (P60) mice for 6 months. During this time we administered BrdU for 4 months, followed by a 2 -month chase. We analyzed whole mount preparations of the distal ileum of 4 mice that had undergone voluntary running but did not observe any convincingly $\mathrm{BrdU}^{+} \mathrm{HuD}^{+}$neurons in either the myenteric or submucosal plexus of these mice (Table 1 and Figure 2A). Importantly, we did observe $\mathrm{BrdU}^{+} \mathrm{S} 100 \mathrm{~B}^{+}$cells with small nuclei in myenteric ganglia from these mice, indicating that BrdU was detectably incorporated into ENS progenitors in these experiments and that gliogenesis did occur in the adult ENS (Figure 2A). These results suggest that dietary changes and voluntary exercise either do not stimulate detectable levels of neurogenesis in the adult ENS or that the neurogenesis only occurs without cell division.

If neurogenesis occurs in the ENS in response to gut injury, it might be stimulated by inflammation. To test this we induced inflammation in the guts of adult (P60) mice by administering indomethacin, dextran sodium sulfate (DSS), oral Citrobacter rodentium, or oral Yersinia pseudotuberculosis (see Supplemental Methods for details). In each case, BrdU was administered to the treated mice for 6 weeks, followed by a 2 -week chase without BrdU. Whole mount preparations of the distal ileum and the gut regions that experienced the greatest levels of inflammation (colon, proximal small intestine, stomach, and cecum) were stained with antibodies against BrdU and HuD. Gut inflammation was evidenced in the expected regions by a thickening of the smooth muscle layer, adhesions between the smooth muscle layer and the gut epithelium/submucosa, and infiltration of inflammatory cells (data not shown). We analyzed thousands of neurons in the myenteric and/or submucosal plexus from each of 4 mice per treatment and did not observe any convincing $\mathrm{BrdU}^{+} \mathrm{HuD}^{+}$neurons in any region of the stomach or large or small intestine (Table 1 and Figure 2, B-E). We did observe $\mathrm{BrdU}^{+} \mathrm{S} 100 \mathrm{~B}^{+}$glia in myenteric ganglia from mice in each of these treatments (Supplemental Figure 6, A-C). These results suggest that gliogenesis occurs within the inflamed gut but that inflammation does not stimulate detectable neurogenesis in the adult ENS.

ENS injury promotes only limited gut neurogenesis. To test whether adult neurogenesis is induced by ENS injury, we administered BrdU to rats and mice after inducing various gut injuries. Benzalkonium chloride (BAC) is a neurotoxic detergent that ablates enteric neurons and glia in a well-defined area of the myenteric plexus shortly after treatment when painted onto the serosal surface of the gut (43, $50)$. We treated a short segment of the distal ileum with either BAC (dissolved in $0.9 \%$ saline) or saline alone and administered BrdU for 10 days to 19 weeks following BAC treatment to label newly generated neurons. This was chased by a 2 -week to 11 -month period with- out BrdU. In some animals, treated or untreated with BAC, osmotic minipumps were implanted into the abdomen to release EGF and FGF, or GDNF, in case these growth factors might stimulate neurogenesis. Overall, a total of 70 rats and 15 mice were examined in these experiments (see Table 1 for a detailed description of treatments). In 84 of 85 animals, we did not detect any convincingly $\mathrm{BrdU}^{+} \mathrm{HuD}^{+}$ neurons in the myenteric or submucosal plexus from the normal ileum of control animals (Figure $3 \mathrm{~A}$ and Table 1), healthy regions of the gut near the sites of BAC injury (Figure $3 \mathrm{~B}$ and Table 1), gut regions that bordered the sites of BAC injury (Figure $3 \mathrm{C}$ and Table 1), or within the injured regions themselves (Figure $3 \mathrm{D}$ and Table 1). Even months after BAC treatment, we generally did not observe any neurons within the gut region treated with BAC (Figure 3D). In the cases in which rare residual neurons were observed within regions treated with $\mathrm{BAC}$, they were not $\mathrm{BrdU}^{+}$, suggesting that myenteric neurons were generally not regenerated within the ablated region.

In contrast to the results obtained with most rats and mice, we did observe convincingly $\mathrm{BrdU}+\mathrm{HuC} / \mathrm{D}^{+}$enteric neurons in a single male rat that had been treated with BAC, pulsed with BrdU for 10 days after BAC treatment, then chased without BrdU for 3 weeks prior to analysis (Supplemental Figure 7 and Table 1). In this rat, $6.1 \%$ of the $\mathrm{HuC} / \mathrm{D}^{+}$neurons in the injured region of the gut were $\mathrm{BrdU}^{+}$, and $4.7 \%$ of the neurons $1 \mathrm{~cm}$ away from the injured region were $\mathrm{BrdU}^{+}$. Despite extensive effort, we were not able to replicate the neurogenesis that was observed in this rat. These data suggest that neurogenesis with cell division can occur within the ENS in response to BAC treatment, but that this neurogenic response is observed in only restricted circumstances.

We also assessed whether ENS neurogenesis could be observed in other ENS injury models. We partially ablated enteric glia using transgenic mice expressing the herpes simplex virus thymidine kinase (HSV-TK) under the control of the mouse Gfap promoter (51). To induce the injury, we administered ganciclovir to wild-type or Gfap-tk transgenic mice for 1-4 weeks, immediately followed by a 10- to 14-day pulse of BrdU and a 2- to 3-week chase without BrdU. Despite examining 10 sections through the distal ileum of each of 8 mice in this experiment, we did not observe any convincing $\mathrm{BrdU}{ }^{+} \mathrm{HuC} / \mathrm{D}^{+}$neurons in the myenteric or submucosal plexus (Table 1). We also lethally irradiated two young adult mice (followed by hematopoietic stem cell transplantation to prevent death) and performed partial gut stenosis on two young adult rats, then administered BrdU for 2-3 weeks, followed by 2 weeks chase, but did not observe any convincingly $\mathrm{BrdU} \mathrm{H}^{+} \mathrm{HuC} / \mathrm{D}^{+}$enteric neurons in the distal ileum of any of these animals (Table 1). In total, we assayed ENS neurogenesis in 51 adult mice and 108 adult rats and only found convincing neurogenesis in the ENS of one rat. These data suggest that neurogenesis occurs only in restricted circumstances within the adult gut, even after injury.

Lineage tracing did not yield compelling evidence for adult ENS neurogenesis. If new ENS neurons were generated by direct differentiation of enteric glia into neurons, without cell division, we would not have detected this by BrdU incorporation. To address this possibility, we looked for evidence of adult neurogenesis by lineage tracing by mating GFAP-Cre (52) or GFAP-CreERT2 mice (53) with RosaloxpEYFP conditional reporter mice (54). As shown in Figure 1, $\mathrm{H}$ and I, all or virtually all of the $\mathrm{CD} 49 \mathrm{~b}^{+}$adult gut cells that formed neurons in culture were also $\mathrm{GFAP}^{+}$. Therefore, if these cells engage in adult neurogenesis, with or without cell division, we should observe an increase in the frequency of $\mathrm{EYFP}^{+}$neurons 

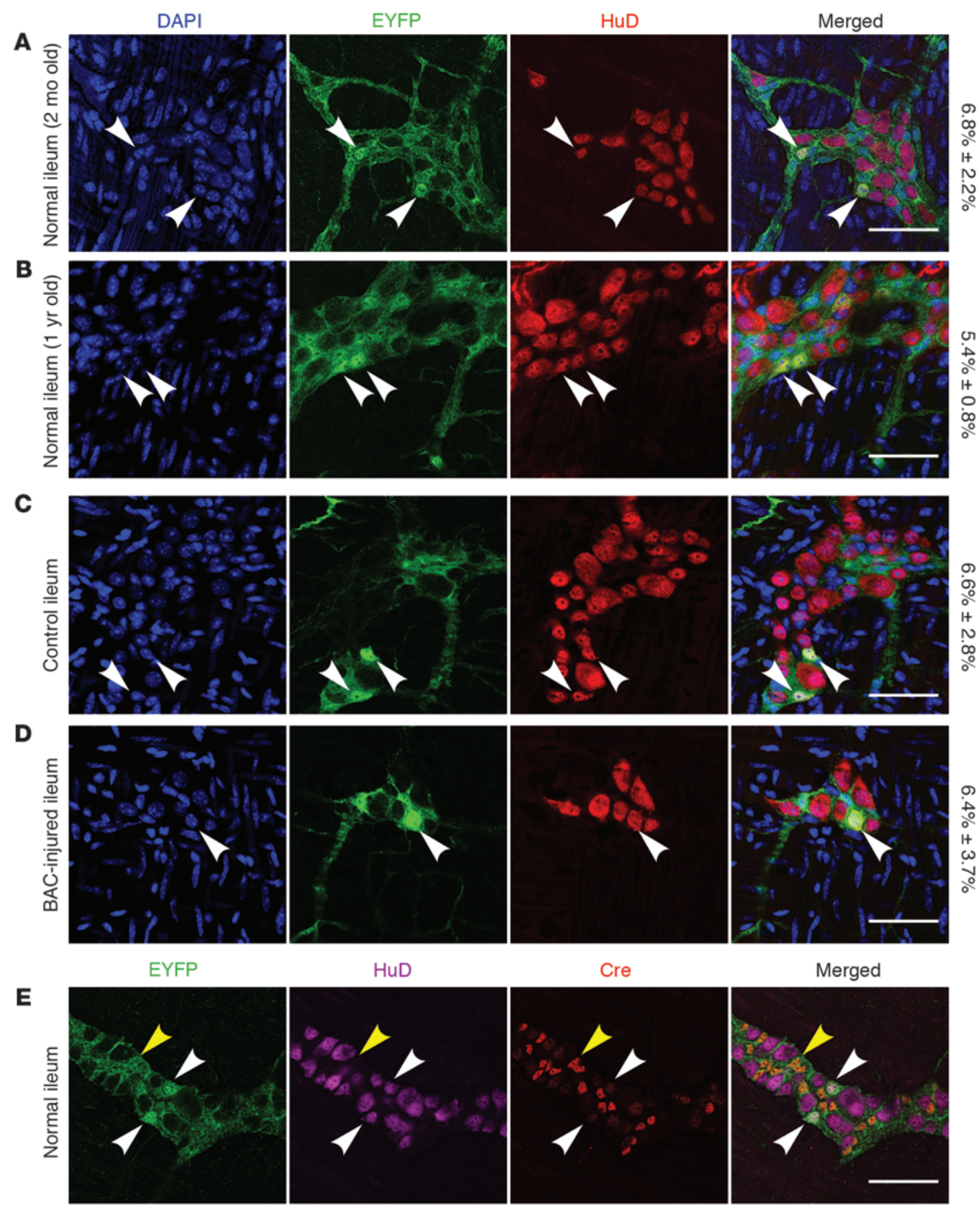

Figure 4

Lineage tracing in GFAP-Cre;Rosa-loxpEYFP mice failed to detect clear evidence of ENS neurogenesis in healthy or BAC-treated adult mice. To assess whether new neurons arise from GFAP+ enteric glia during adulthood, we performed lineage tracing in GFAP-Cre;Rosa-loxpEYFP mice. EYFP+HuD ${ }^{+}$neurons were counted in healthy young $(\mathbf{A} ; 2$ months) and old (B; 12 months) mice as well as in mice treated with topical applications of saline (C) or BAC (D). Three mice were analyzed per treatment, with more than 1,000 HuD+ neurons analyzed per mouse. The numbers on the right represent the percentage of $\mathrm{HuD}^{+}$neurons that were $\mathrm{EYFP}^{+}$from each treatment (mean $\pm \mathrm{SD}$ ). BAC-treated mice were analyzed 6-8 months after treatment. (A-D) EYFP+HuD+enteric neurons (white arrowheads) were observed in the myenteric plexus of all mice in all treatments. However, the frequency of EYFP+ neurons did not increase with age (B) or in regions bordering on BAC-ablated areas (D) compared with normal young adult mice (A) or control mice (C), respectively. EYFP+ neurons therefore arose in GFAP-Cre;Rosa-loxpEYFP mice prior to 2 months of age, but few new neurons were generated from GFAP+ cells in the adult ENS. (E) EYFP+ neurons (white arrowheads) did not stain positive for Cre recombinase, while EYFP+ glia did (yellow arrowheads), suggesting that EYFP expression was not due to nonspecific expression of Cre recombinase in enteric neurons. Scale bars: $50 \mu \mathrm{m}$. 


\section{Table 2}

Lineage tracing in GFAP-CreERT2;Rosa-IoxpEYFP mice detected little evidence of ENS neurogenesis

\begin{tabular}{|c|c|c|c|c|c|c|}
\hline $\begin{array}{l}\text { Type of } \\
\text { injury }\end{array}$ & $\begin{array}{l}\text { Age at onset } \\
\text { of experiment }\end{array}$ & $\begin{array}{c}\text { Age at } \\
\text { analysis }\end{array}$ & Tissue & Mice $(n)$ & $\begin{array}{l}\text { Time on } \\
\text { tamoxifen }\end{array}$ & $\%$ EYFP+ neurons \\
\hline No surgery & $2-4$ mo & $10 \mathrm{mo}$ & Myenteric plexus & 3 & $6-8 \mathrm{mo}$ & $0.11 \% \pm 0.15 \%$ \\
\hline $\mathrm{BAC}$ & 2-4 mo & $10 \mathrm{mo}$ & Myenteric plexus (border region) & 3 & $6-8 \mathrm{mo}$ & $0.053 \% \pm 0.014 \%$ \\
\hline $\mathrm{BAC}$ & $11 \mathrm{mo}$ & $15-17 \mathrm{mo}$ & Myenteric plexus (border region) & 9 & $4-6$ mo & $0.028 \% \pm 0.027 \%$ \\
\hline $\mathrm{BAC}$ & $11 \mathrm{mo}$ & $15-17 \mathrm{mo}$ & Myenteric plexus (healthy region) & 5 & $4-6 \mathrm{mo}$ & $0.030 \% \pm 0.022 \%$ \\
\hline
\end{tabular}

To assess whether new neurons arose from GFAP+ enteric glia during adulthood, we treated GFAP-CreERT2;Rosa-loxpEYFP mice with tamoxifen for 4-8 months. EYFP+HuD+ neurons were counted in healthy control mice and in mice treated with topical BAC. A very low percentage $(0.028 \%-0.11 \%)$ of $\mathrm{HuD}^{+}$ neurons was EYFP+ in all treatments, irrespective of BAC treatment.

in the adult gut of GFAP-Cre;Rosa-loxpEYFP or GFAP-CreERT2;RosaloxpEYFP mice with age.

In 2- to 4-month-old GFAP-Cre;Rosa-loxpEYFP transgenic mice, $90 \% \pm 3 \%$ of $\mathrm{GFAP}^{+}$enteric glia were $\mathrm{EYFP}^{+}$, indicating efficient recombination in GFAP-expressing cells. In comparison, $6.8 \% \pm 2.2 \%$ of $\mathrm{HuD}^{+}$neurons in the myenteric plexus of 2 -month-old adult transgenic mice were $\mathrm{EYFP}^{+}$(Figure 4A). The labeling of enteric neurons by EYFP was not due to nonspecific expression of Cre recombinase within the $\mathrm{HuD}^{+}$neurons themselves, as Cre expression was observed in enteric glia but not in $\mathrm{HuD}^{+}$neurons (Figure 4E). Therefore, the $\mathrm{EYFP}^{+}$enteric neurons in these young adult mice had to have arisen before 2 months of age, most likely by the first month after birth, when the vast majority of enteric neurogenesis is completed (45). If significant numbers of enteric neurons were generated from GFAPexpressing cells after 2-4 months of age, we would expect the frequency of $\mathrm{EYFP}^{+}$neurons to increase with age. However, when we examined 1-year-old GFAP-Cre;Rosa-loxpEYFP mice, we found only
$5.4 \% \pm 0.8 \%$ of neurons in the myenteric plexus that were labeled with EYFP (Figure 4B). We did not, therefore, detect any increase over time in the frequency of $\mathrm{EYFP}^{+}$neurons in the ENS. Although $\mathrm{EYFP}^{+}$ enteric neurons were generated from GFAP-expressing cells prior to 2 months of age in GFAP-Cre;Rosa-loxpEYFP mice, there appears to be little further differentiation of GFAP-expressing cells into myenteric neurons after 2-4 months of age in the normal gut.

To test whether ENS injury could induce neurogenesis by GFAPexpressing cells, we treated GFAP-Cre;Rosa-loxpEYFP transgenic mice with $\mathrm{BAC}$ and analyzed the frequencies of $\mathrm{EYFP}^{+}$enteric neurons in the myenteric plexus 6-8 months after BAC treatment. The average frequency of $\mathrm{EYFP}^{+}$neurons adjacent to the injured region $(6.4 \% \pm 3.7 \%$, Figure 4D) was not greater than the average frequency of neurons observed in mice that were not injured $(6.6 \% \pm 2.8 \%$, Figure $4 \mathrm{C})$. Thus, we did not observe an increase in $\mathrm{EYFP}^{+}$neurons, as would have been expected if neurogenesis were induced from GFAP-expressing cells in the injured region of the gut after BAC treatment.
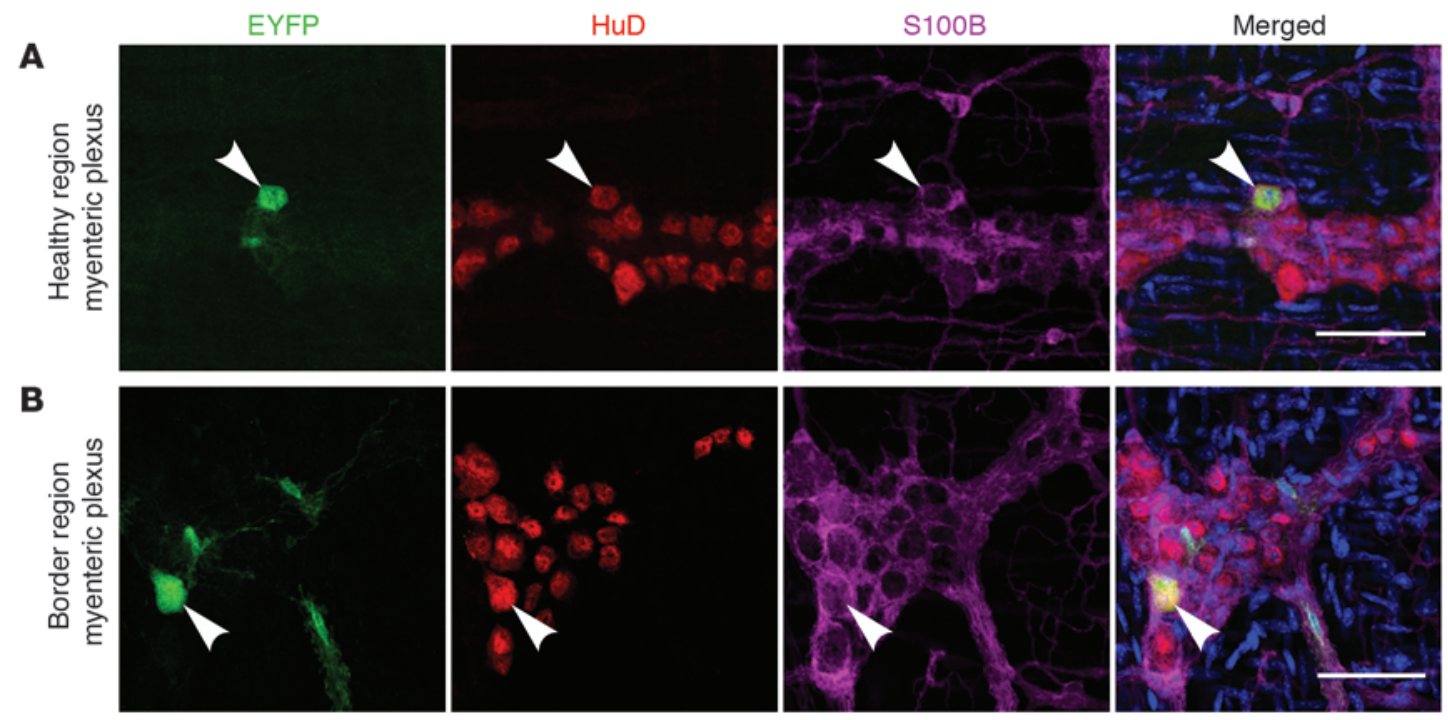

\section{Figure 5}

Lineage tracing in adult GFAP-CreERT2;Rosa-loxpEYFP mice detected little ENS neurogenesis after BAC treatment. To assess whether new neurons arise from GFAP+ enteric glia during adulthood, we treated GFAP-CreERT2;Rosa-loxpEYFP mice with BAC to ablate myenteric neurons and then with tamoxifen for 4-8 months. EYFP+HuD+ neurons (white arrowheads) were counted in a healthy region of the gut (A), as well as in a border region immediately adjacent to the BAC-ablated area (B). The frequency of EYFP+HuD+ neurons was not increased in the border region immediately adjacent to the BAC-ablated area $(B ; 0.028 \% \pm 0.027 \%$, see Table 2$)$ as compared with a healthy segment of gut in the same mice $(\mathbf{A} ; 0.030 \% \pm 0.022 \%$, see Table 2$)$. It is not clear whether this reflects the generation of rare neurons in the adult ENS in a manner that is not influenced by BAC injury, or the ectopic expression of Cre recombinase in rare neurons. Scale bars: $50 \mu \mathrm{m}$. 

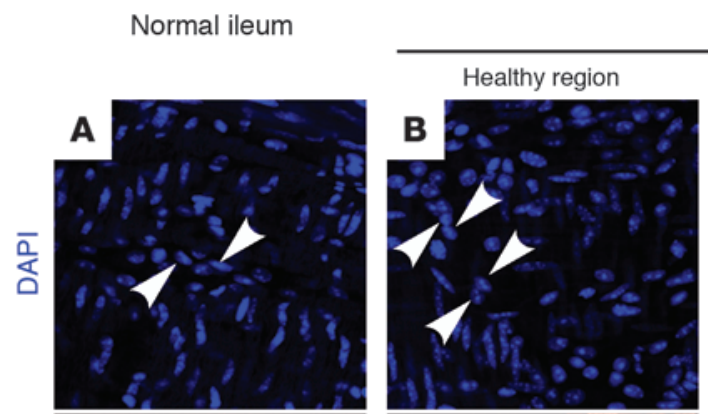

BAC-injured ileum
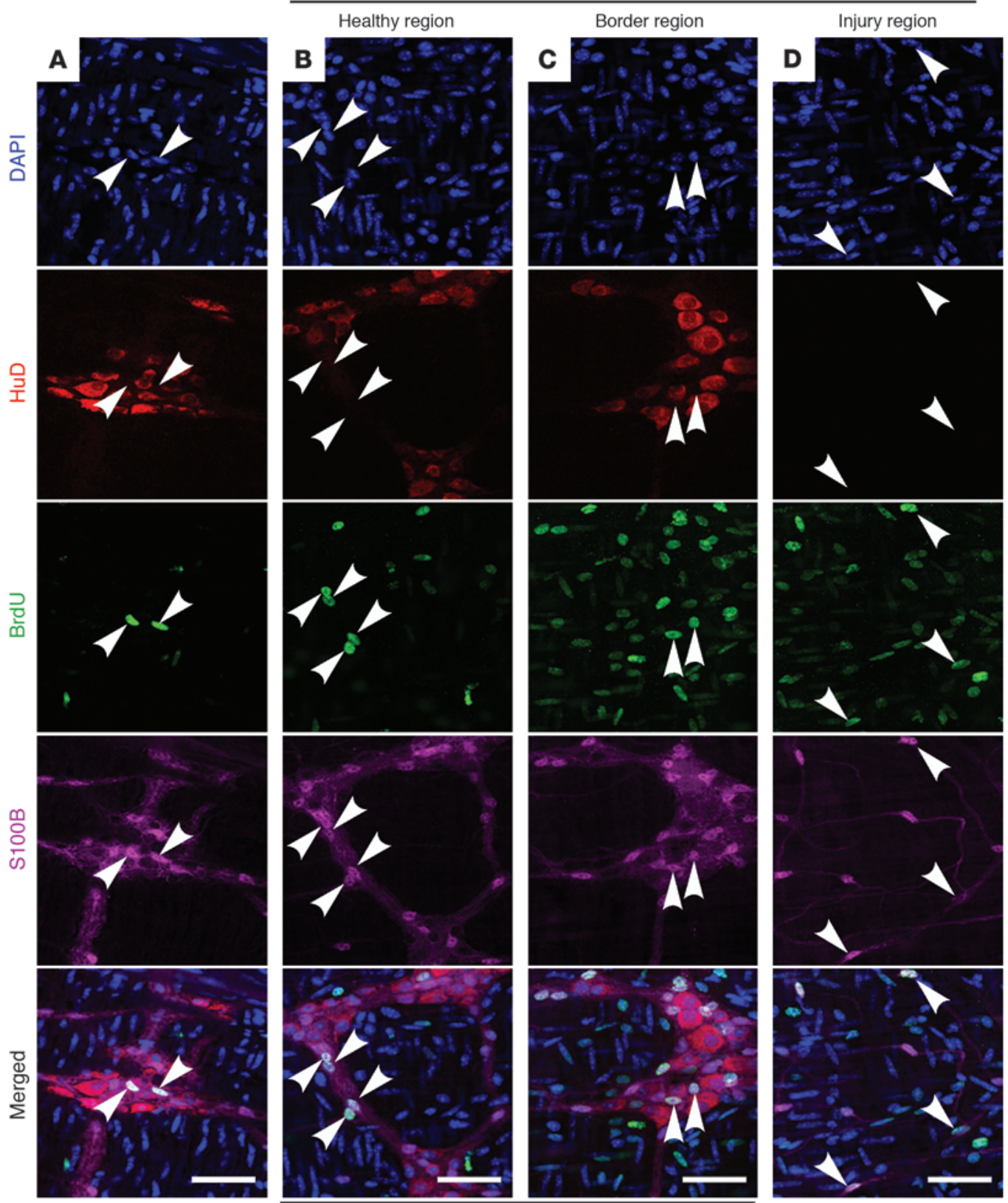

$2.8 \% \pm 0.3 \%$

$36 \% \pm 7 \%$

$90 \% \pm 2 \%$

Figure 6

Gliogenesis occurs in the adult ENS under steady-state conditions and in response to injury. Whole mount staining of the myenteric plexus with DAPI (blue) and with antibodies against HuD (red), BrdU (green), and S100B (magenta) from normal adult mice (A) and mice that underwent focal ablation of the myenteric plexus by topical BAC treatment (B-D). BrdU was administered for 6 weeks, followed by a chase without BrdU for 6 weeks in A; and administered for 10 weeks, followed by a chase without BrdU for 3 weeks in B-D. Three mice were analyzed per treatment, with $2,000-4,000$ glial cells counted per mouse. (A) $2.8 \% \pm 0.3 \%$ of $\mathrm{S}_{100 \mathrm{~B}^{+}}$glial cells in the myenteric plexus of healthy adult mice were BrdU+ after 6 weeks of BrdU treatment, indicating that gliogenesis does occur under steady-state conditions in the adult ENS. (B and C) Compared with

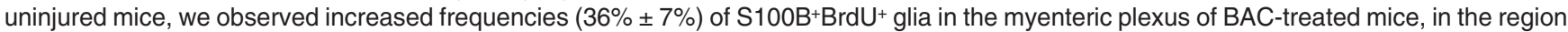

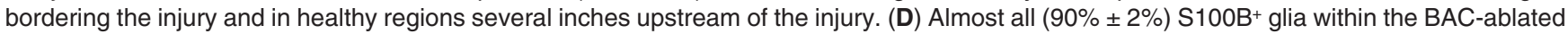
region were $\mathrm{BrdU}^{+}$, suggesting a regenerative response to restore glia to the ablated region. Numbers on the bottom indicate the frequency of

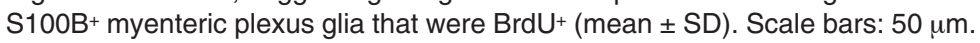


To avoid the contribution of $\mathrm{GFAP}^{+}$progenitors to gut neurogenesis during fetal/neonatal development and to directly test whether $\mathrm{GFAP}^{+}$cells give rise to neurons in the adult gut, we studied GFAPCreERT2;Rosa-loxpEYFP mice. In these mice, Cre recombinase activity can be induced in GFAP-expressing cells by tamoxifen administration. We administered tamoxifen for 4 to 8 months to healthy or BAC-treated adult GFAP-CreERT2;Rosa-loxpEYFP mice and stained the gut tissues for $\mathrm{EYFP}^{+}$neurons and glia. The efficiency of Cremediated recombination in these mice was low, as only $3 \%-5 \%$ of all $\mathrm{GFAP}^{+}$enteric glia were labeled with EYFP. We found a very small percentage $(0.028 \%-0.11 \%)$ of $\mathrm{HuD}^{+}$enteric neurons in the myenteric plexus of control and BAC-treated GFAP-CreERT2;Rosa-loxpEYFP mice that were $\mathrm{EYFP}^{+}$(Table 2 and Figure 5). BAC treatment did not increase the frequency of $\mathrm{EYFP}^{+} \mathrm{HuD}^{+}$neurons in the guts of GFAP-CreERT2;Rosa-loxpEYFP mice (Table 2). It is not clear whether these low frequencies of $\mathrm{EYFP}^{+} \mathrm{HuD}^{+}$enteric neurons in GFAPCreERT2;Rosa-loxpEYFP mice reflect low levels of adult neurogenesis that were not detectable by BrdU administration, or whether they reflect nonspecific expression of the Cre recombinase transgene in rare neurons. Either way, our data suggest that little neurogenesis occurs in the normal adult gut under physiological conditions.

Gliogenesis occurs under steady-state conditions in the adult ENS. While we did not consistently detect neurogenesis in the adult ENS, gliogenesis was readily and consistently detected under steady-state conditions (Figure 6A), after BAC injury (Figure 6, B-D), after voluntary exercise (Figure 2A), and within guts inflamed by chemical treatment or infection (Supplemental Figure 6). In healthy, normal adult mice administered BrdU for 6 weeks followed by a 6 -week chase, $2.8 \% \pm 0.3 \% \mathrm{~S} 100 \mathrm{~B}^{+}$glia in the myenteric plexus were $\mathrm{BrdU}^{+}$ (Figure 6A). When BAC-treated mice were administered a 10-week

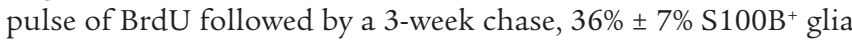
in the myenteric plexus were $\mathrm{BrdU}^{+}$in a nearby healthy region of gut as well as in the region that bordered the BAC-ablated region (Figure $6, \mathrm{~B}$ and $\mathrm{C}$ ). However, $90 \% \pm 2 \%$ of the $\mathrm{S}_{100 \mathrm{~B}^{+}}$glia within the ablated region of the myenteric plexus were $\mathrm{BrdU}^{+}$(Figure 6D). These data demonstrate there is considerable gliogenesis under physiological conditions in the adult gut and that the rate of gliogenesis increases after certain types of ENS injury. These results suggest that the primary physiological role for the progenitor activity retained by enteric glia is to form new glia under steadystate conditions and after injury.

\section{Discussion}

We and others previously demonstrated that self-renewing and multipotent cells with properties similar to those of NCSCs persist throughout adult life in the mammalian ENS (33-39). These cells proliferate extensively and give rise to PNS neurons, glia, and myofibroblasts in culture, forming colonies similar to those formed by fetal NCSCs (32). These cells also express the NCSC marker p75 and upon transplantation into chick embryos migrate through the neural crest migration pathway to form neurons and glia (33). Although our prior studies suggested that these cells reside in or near the myenteric plexus, the identity, localization, and physiological function of these cells remained uncertain, partly because $\mathrm{p} 75$ alone was not sufficient for the unambiguous identification of these cells (33).

In the current study, we discovered that these cells could be isolated to a high degree of purity using CD49b (integrin $\alpha 2$ ) (Figure 1C). Nearly all CD 49b ${ }^{+}$Lin $^{-}$cells expressed nestin, SOX10, S100B, GFAP, and p75, markers of NCSCs and/or enteric glia, but not the neuronal marker HuD (Figure 1, H and I). Staining of whole mount preparations of the myenteric plexus revealed that most staining of CD49b overlapped with S100B, p75, GFAP, and nestin within myenteric ganglia in a pattern consistent with enteric glia (Figure 1J and Supplemental Figure 2, C-E). Many enteric glia, therefore, have the potential to form multilineage colonies in culture, and the cells we previously identified as adult gut NCSCs (33) could also be considered enteric glia.

The observation that about $60 \%$ of $\mathrm{Lin}^{-} \mathrm{S}_{100 \mathrm{~B}^{+}}$or $\mathrm{Lin}^{-} \mathrm{GFAP}^{+}$ enteric glia stained positive for CD49b (Supplemental Figure 2B) and that $44 \%$ of $\mathrm{CD}^{2} 9 \mathrm{~b}^{+} \mathrm{Lin}^{-}$cells formed multipotent neurospheres in culture (Figure 1C) raises the possibility that adult enteric glia may be heterogeneous. It is possible that a minority of enteric glia are capable of forming multilineage colonies in culture and that these cells represent a distinct subpopulation. Nonetheless, our data indicate that this would represent a major subpopulation of enteric glia (at least $60 \% \times 44 \%=26 \%$ ).

Using BrdU incorporation assays, we readily detected neurogenesis in the CNS dentate gyrus (Supplemental Figure 3) but generally failed to detect neurogenesis in the adult ENS of the same rats (Table 1). We administered BrdU to many mice and rats in a variety of different circumstances including normal young adults, old adults, pregnant rats, hyperglycemic rats, rats undergoing dietary changes, mice undergoing voluntary exercise, mice with gut inflammation due to bacterial infection or chemical treatment, rodents with focal ablation of the myenteric plexus due to topical BAC treatment, Gfap-tk mice after ablation of enteric glia, and rats with osmotic minipumps that released growth factors into their peritoneum. We administered BrdU to these rodents for variable periods of time, from 10 days to 19 weeks. Yet in no case did we consistently observe new neurons. The only exception was a single rat with a focal ablation of the myenteric plexus from topical BAC treatment, which did have convincingly $\mathrm{BrdU}+\mathrm{HuC} / \mathrm{D}^{+}$neurons (Supplemental Figure 7). However, we were never able to replicate that observation, despite examining 58 additional rats and mice that had been treated with BAC. These results suggest that cells capable of forming new neurons persist within the adult gut but that little neurogenesis occurs under the conditions we studied.

Given that neurogenesis occurs in the adult gut after administration of exogenous $5-\mathrm{HT}_{4}$ agonist (46), it remains possible that there are some physiological circumstances in which endogenous $5-\mathrm{HT}_{4}$ agonists and gut neurogenesis are induced. However, Liu et al. (46) also did not observe the formation of new neurons upon BrdU administration in the normal adult gut in the absence of exogenous $5-\mathrm{HT}_{4}$ agonist. It remains unknown what physiological circumstances might induce higher levels of 5- $\mathrm{HT}_{4}$ agonists in the adult gut.

We also performed lineage-tracing studies using GFAP-Cre and GFAP-CreERT2 mice to test whether $\mathrm{GFAP}^{+}$enteric glia could give rise to neurons in the adult gut, with or without cell division. The frequency of $\mathrm{EYFP}^{+}$myenteric neurons in the guts of adult GFAPCre;Rosa-loxpEYFP mice did not increase during aging or after BAC treatment, despite efficient labeling of $90 \% \pm 3 \%$ of $\mathrm{GFAP}^{+}$glia in these mice (Figure 4). This suggested that few new neurons are generated by $\mathrm{GFAP}^{+}$cells during adulthood. We obtained similar results in GFAP-CreERT2;Rosa-loxpEYFP mice, in which only rare neurons were $\mathrm{EYFP}^{+}$under steady-state conditions or after BAC treatment (Figure 5 and Table 2). These results therefore complement the results of the BrdU incorporation studies in suggesting that there is little neurogenesis in the adult ENS under the physiological conditions that we studied. On the other hand, our data leave open the possibility that $\mathrm{GFAP}^{-}$progenitors might be able to 
engage in neurogenesis without cell division or that neurogenesis occurs under circumstances we did not study.

In a companion to the present article, Laranjeira et al. did report neurogenesis at the border of injured regions of the distal ileum after BAC treatment of adult mice (55). The authors observed this neurogenesis by lineage tracing SOX $10^{+}$gut cells in Sox10-CreER mice (55). Consistent with our results, they never observed neurogenesis in the adult gut after 1-3 months of age in the absence of injury and could not detect the injury-induced neurogenesis by fate mapping with GFAP-CreERT2 (55). In principle, Sox10-CreER should fate map the same $\mathrm{GFAP}^{+}$cells that we studied, as most enteric glia are $\mathrm{CD}_{4} \mathrm{~b}^{+}, \mathrm{GFAP}^{+}$, and SOX10+ (Figure 1). However, if small numbers of neurons are generated without cell division after BAC treatment, it is possible we were unable to detect these cells in the background of $\mathrm{EYFP}^{+}$neurons generated during development in GFAP-Cre mice and that the efficiency of recombination was too low in adult GFAPCreERT2 mice to detect these cells. It is also possible that a rare population of $\mathrm{SOX} 10^{+} \mathrm{GFAP}^{-}$progenitors may exist and may contribute to adult gut neurogenesis without undergoing cell division. Overall, neurogenesis may occur in the adult gut in response to certain injuries, though it is not clear what kinds of injuries might occur under physiological conditions that are mimicked by BAC treatment. Our data suggest that the adult ENS does not have constitutive neurogenesis by dividing progenitors, unlike the CNS.

We readily observed gliogenesis under steady-state conditions and in response to injury (Figure 2A and Figure 6). While most enteric glia were quiescent at any one time (Figure $1 \mathrm{~K}$ ), at least some of these cells appeared to be recruited into cycle, as $2.8 \% \pm 0.3 \%$ of enteric glia were $\mathrm{BrdU}^{+}$after 6 weeks of BrdU administration (Figure 6). This suggests a low level turnover of enteric glia under steady-state conditions as well as considerable capacity to regenerate glia after injury (Figure 6). Our data suggest that the primary progenitor function of enteric glia is to form new glia in the ENS throughout adult life. The fact that Gfap-tk mice die with degeneration of the myenteric plexus after sustained ganciclovir treatment implies that this adult gliogenesis is critical for the maintenance of ENS function, as ganciclovir preferentially kills dividing cells (51).

Although we did not generally observe regeneration of new neurons in the injured gut after BAC injury (Figure 3D), we did observe extensive regeneration of nerve fibers in the injured region, in association with a re-colonization of the injured region by glia (data not shown). It is unclear whether this contributed to a recovery of ENS function, though it does raise the possibility that ENS function may be restored more through a regeneration of axons and a rewiring of existing circuits than by generation of new neurons. Hanani et al. also reported the regeneration of nerve fibers in close association with glia in BAC-injured regions of the gut, though they observed morphological evidence for the regeneration of neurons in the injured region, which we did not detect (43).

In stark contrast to our failure to consistently observe neurogenesis in vivo, adult $\mathrm{CD}_{4} 9 \mathrm{~b}^{+}$enteric glia readily formed neurons in culture (Figure 1F). This raises the question of what mechanisms stimulate this latent neurogenic potential in culture and not generally in vivo. One possibility is that the culture medium contains factors that promote the dedifferentiation of enteric glia into multipotent cells; however, freshly isolated, uncultured adult rat gut p $75^{+}$cells form neurons after transplantation into chick embryos, albeit in smaller numbers than fetal $\mathrm{p} 75^{+} \mathrm{NCSCs}$ (33). This suggests that even uncultured adult enteric glia (which are $\mathrm{p} 75^{+}$in addition to being $\mathrm{CD}_{4} 9 \mathrm{~b}^{+}, \mathrm{GFAP}^{+}$, and $\mathrm{S} 100 \mathrm{~B}^{+}$; Figure 1 and Sup- plemental Figure 2) have neurogenic potential, though the chick embryo may also reprogram these cells. Alternatively, it is possible that $\mathrm{CD}_{49} \mathrm{~b}^{+}$adult enteric glia are bona fide multipotent progenitors that possess intrinsic neurogenic potential; however, the adult ENS may lack the signals required to promote neuronal differentiation by these cells. The observation that serotonin receptor agonists can induce neurogenesis in the adult ENS (46) raises the possibility that serotonin receptor stimulation may be inadequate for neurogenesis in the adult gut under most physiological conditions and that serotonin from chick embryo extract may promote the elevated levels of neurogenesis observed in culture. It is also possible that the adult ENS is not permissive for neurogenesis in vivo due to inhibitory signals.

Our data suggest that many adult enteric glia are capable of generating multipotent, self-renewing colonies in culture, similar to NCSCs. However, we observed little or no adult neurogenesis under physiological conditions in the ENS. Low levels of neurogenesis may occur in response to certain types of injury or under restricted circumstances. However, the primary physiological function of the progenitor activity retained by adult enteric glia is to form new glia under steady-state conditions and to regenerate glia that are lost to injury. The robust gliogenesis that we observed is likely necessary to maintain adult ENS and gut function.

\section{Methods}

Mice and rats. NCSC isolation and in vivo BrdU incorporation experiments were performed using C57BL/6J mice and Sprague-Dawley rats (Charles River) housed in the Unit for Laboratory Animal Medicine at the University of Michigan. GFAP-CreERT2 mice (53) used for lineage tracing experiments were provided by Frank Kirchhoff (Max Planck Institute of Experimental Medicine, Göttingen, Germany). FVB-Tg(GFAP-Cre)25Mes/J mice (GFAPCre mice) (52) and B6.129X1-Gt(ROSA)26Sortm $1(E Y F P) \mathrm{Cos} / \mathrm{J}$ mice (RosaloxpEYFP mice) (54) were obtained from The Jackson Laboratory. Gfap-tk mice (51) were provided by Michael Sofroniew (David Geffen School of Medicine, UCLA, Los Angeles, California, USA). Streptozotocin-induced hyperglycemic Sprague-Dawley rats were provided by John Wiley (University of Michigan, Ann Arbor).

Gut lesions and BrdU administration in vivo. For BrdU administration in all experiments, mice and rats were given an initial i.p. injection of BrdU (Sigma-Aldrich) at $50 \mu \mathrm{g} / \mathrm{g}$ body weight, followed by BrdU in the drinking water $(0.5 \mathrm{mg} / \mathrm{ml}$ for mice and $1.0 \mathrm{mg} / \mathrm{ml}$ for rats) for the time periods indicated in Table 1 to mark dividing cells. BrdU was then removed from the drinking water, and animals were allowed to drink regular water to "chase" the BrdU from rapidly dividing cells such as gut epithelial cells. This allowed us to mark cells that divided then differentiated during the period of BrdU administration.

To induce gut lesions using survival surgeries, we anesthetized animals by i.p. injection of $100 \mathrm{mg} / \mathrm{kg}$ ketamine and $10 \mathrm{mg} / \mathrm{kg}$ xylazine. After shaving the abdomen and sterilizing with Betadine solution, we made a 1.5- to 2 -cm ventral midline incision in order to mobilize a segment of distal ileum and perform the procedures described below. Following all survival surgeries, analgesic (buprenorphine, $2 \mathrm{mg} / \mathrm{kg}$ ) was administered subcutaneously, and recovery from anesthetic was monitored closely. Antibiotic water ( $1.1 \mathrm{~g} / \mathrm{l}$ neomycin sulfate and $10^{6} \mathrm{U} / 1$ polymyxin B sulfate; Sigma-Aldrich) was administered for 1 week following surgery, and wound healing was monitored twice daily for 7 days.

For BAC (Sigma-Aldrich) injuries in rats, $0.1 \%$ BAC in $0.9 \%$ saline or $0.9 \%$ saline alone was painted onto the serosal surface of a 2- to 3-cm segment of distal ileum as previously described (50). For BAC injuries in mice, a small piece of filter paper (approximately $3 \mathrm{~mm} \times 15 \mathrm{~mm}$ ) was soaked with $0.1 \%$ 
$\mathrm{BAC} / 0.9 \%$ saline solution or saline alone and laid on top of the serosal surface of the distal ileum approximately $5 \mathrm{~mm}$ proximal to the ileocecal junction. The filter paper was kept moist, but not dripping, with BAC solution and left in place for 5-10 minutes. This resulted in a well-defined region of injury to the underlying myenteric plexus on one side of the gut wall. In some experiments $0.05 \% \mathrm{BAC}$ was dissolved in Krebs solution $(118 \mathrm{mM}$ $\mathrm{NaCl}, 4.7 \mathrm{mM} \mathrm{KCl}, 1.2 \mathrm{mM} \mathrm{MgSO}_{4}, 1.5 \mathrm{mM} \mathrm{NaH}_{2} \mathrm{PO}_{4}, 14.5 \mathrm{mM} \mathrm{NaHCO}_{3}$, $11.5 \mathrm{mM}$ glucose, and $2.5 \mathrm{mM} \mathrm{CaCl}_{2}$ ) instead of $0.9 \%$ saline as described in a prior study (43). A non-absorbable stitch was sometimes used to mark the area of injury. The injured segment was thoroughly rinsed with $5 \mathrm{ml}$ saline 3 times to minimize the spread of BAC through the abdomen; the ileum was then placed back into the abdomen, and the midline incision was closed with a layer of absorbable sutures for the muscle and another layer of non-absorbable sutures for the skin. In some experiments, a sterile osmotic minipump (ALZET osmotic pumps; Durect Corp.) was placed into the abdomen before closing to deliver growth factors, to test whether growth factor administration could induce adult ENS neurogenesis similar to what was observed in the CNS (26). Osmotic minipumps were filled with either vehicle solution alone $(0.5 \mathrm{mg} / \mathrm{ml}$ BSA in PBS [Invitrogen], sterile filtered) or vehicle solution with growth factors (FGF and EGF, or GDNF, resulting in a delivery of $60 \mathrm{ng}$ of each growth factor per hour for 7 days). BrdU treatment was started on the day after surgery and continued for 10 days to 19 weeks, then chased, as detailed in Table 1 .

Lineage tracing. GFAP-Cre mice (52) were crossed with Rosa-loxpEYFP mice (54) to label all progeny of GFAP-expressing cells in the ENS during embryonic and postnatal development. To assess the level of neurogenesis by GFAP-expressing cells in the adult ENS, we administered tamoxifencontaining food $(0.4 \mathrm{~g} / \mathrm{kg}$, Harlan) to adult GFAP-CreERT2;Rosa-loxpEYFP double-transgenic mice for 4-6 months to induce Cre recombinase activity in GFAP-expressing cells.

Tissue preparation and immunohistochemistry. Tissue samples used to analyze adult neurogenesis and gliogenesis were from the distal ileum unless otherwise indicated. To cryosection gut tissues, the gut was fixed in $4 \%$ paraformaldehyde overnight, rinsed with PBS, then cryoprotected in $15 \%$ sucrose overnight, embedded in $7.5 \%$ gelatin $/ 15 \%$ sucrose, and flash frozen. Ten- to $15-\mu \mathrm{m}$ frozen sections were cut on a Leica $3050 \mathrm{~S}$ cryostat. Gut blocks were cut longitudinally to increase the number of enteric neurons per section. Sections were allowed to dry for 1 hour before being stained or stored at $-80^{\circ} \mathrm{C}$.

For BrdU staining on tissue sections, slides were rehydrated in PBS, incubated in PBS at $37^{\circ} \mathrm{C}$ to remove gelatin, then rinsed again in PBS. DNA was denatured in $2 \mathrm{~N} \mathrm{HCl}$ for 30-45 minutes at room temperature and neutralized with $0.1 \mathrm{M}$ sodium tetraborate ( $\mathrm{pH} 8.5$ ) for 10 minutes. Sections were rinsed in PBS and pre-blocked in PGN solution (PBS supplemented with $5 \%$ goat serum [Invitrogen], 1\% BSA, 0.3\% Triton X-100 [Sigma-Aldrich], and $0.1 \% \mathrm{NaN}_{3}$ [Sigma-Aldrich]) for 1 hour, then incubated in primary antibodies (diluted in PGN) against $\mathrm{BrdU}$ and $\mathrm{HuC} / \mathrm{D}$ overnight at $4{ }^{\circ} \mathrm{C}$, followed by secondary antibodies for 2 hours at room temperature. Slides were counterstained with $2 \mu \mathrm{g} / \mathrm{ml}$ DAPI for 10 minutes at room temperature, then mounted using ProLong Gold Antifade solution (Invitrogen).

For whole mount staining of adult gut tissues, anesthetized mice were perfused with HBSS-free containing $10 \mathrm{mM}$ EDTA, and $1 \mu \mathrm{M}$ nicardipine (Sigma-Aldrich). Distal ileum or other gut regions were isolated and flushed free of gut contents, and a 3-mm-diameter glass rod was inserted into the gut lumen to fully extend the smooth muscle before the tissue was fixed in 4\% PFA for 20 minutes on ice. The fixed gut tissues were then rinsed in PBS and opened longitudinally along the mesenteries, and the smooth muscle/myenteric plexus layer was separated from submucosal plexus/epithelium layer before each was processed separately for staining.

For staining of intracellular antigens on whole mount tissues, the fixed gut tissues were pre-blocked with PGN for 30 minutes at room temper- ature, followed by staining with primary and secondary antibodies as described above. For simultaneous staining of cell surface and intracellular antigens, a 10-minute permeabilization step with absolute acetone at room temperature was included immediately after tissue fixation, and detergents were excluded from all blocking and washing solution as well as antibody diluents to minimize damage to cell surface antigens. For BrdU staining, DNA was denatured by treating the tissue with $2 \mathrm{~N} \mathrm{HCl}$ for 45 minutes at room temperature after tissue fixation and neutralized with $0.1 \mathrm{M}$ sodium tetraborate ( $\mathrm{pH} 8.5$ ) for 10 minutes. This $\mathrm{HCl}$ denaturation step was performed with the tissue spread flat between glass slides to prevent curling. In all cases, stained whole mount tissues were counterstained with $2 \mu \mathrm{g} / \mathrm{ml}$ DAPI for 10 minutes at room temperature, thoroughly rinsed with PBS, then carefully spread flat onto microscope slides and air dried before being mounted with ProLong Gold Antifade solution. For visualization of the in situ localization of $\mathrm{CD}_{49} \mathrm{~b}^{+}$cells, the smooth muscle/myenteric plexus layer was stained with biotinylated antibody against CD49b and unconjugated antibodies against HuD and S100B. To assess neurogenesis and gliogenesis in healthy animals and after injury, we stained the gut tissues of interest with unconjugated antibodies against BrdU, HuD, S100B, and/ or peripherin. To label the progeny of GFAP-expressing cells and measure Cre recombinase expression in lineage tracing experiments, we stained gut tissues from double transgenic mice with unconjugated antibodies against GFP, HuD, S100B, and Cre (see Supplemental Table 1 for the sources of antibodies). Alexa Fluor 488-, 555-, 594-, and/or 647-conjugated secondary antibodies were used to visualize primary antibody staining. The specificity of primary antibody staining was confirmed by performing isotype control staining on adjacent gut tissues (Supplemental Figure 1).

Statistics. All experiments were performed at least 3 times, and all data are expressed as mean \pm SD. Statistical comparisons between samples were performed in Excel software using 2-tailed Student's $t$ test. A $P$ value less than 0.05 was considered statistically significant.

Study approval. All animal experiments were performed in accordance with protocols approved by the University of Michigan Committee on the Use and Care of Animals (UCUCA).

Detailed methods for cell culture, immunocytochemistry, flow cytometry, additional gut lesion models, and confocal analysis are presented in Supplemental Methods.

\section{Acknowledgments}

This work was supported by the NIH (R01 NS40750 and R01 DK083288) and the Howard Hughes Medical Institute. N.M. Joseph was supported by the National Institute for Neurological Disorders and Stroke (F30 NS049761). E. Quintana was supported by the Spanish Ministry of Education, Culture, and Sports and the European Union Marie Curie Outgoing International Fellowship. Thanks go to John Wiley for providing diabetic rats, to Frank Kirchhoff for providing GFAP-CreERT2 mice, and to Michael Sonofriew for providing Gfap-tk mice; to Roche Pharmaceuticals for providing ganciclovir and Ron Koenig for thoughtful comments on experimental designs; to David Adams and Martin White for assistance with flow cytometry; and to Mark Kiel for assistance with mouse irradiation and reconstitution and Kelly Yeager for general technical assistance.

Received for publication March 25, 2011, and accepted in revised form June 27, 2011.

Address correspondence to: Sean J. Morrison, 5435 Life Sciences Institute, 210 Washtenaw Ave., Ann Arbor, Michigan 481092216, USA. Phone 734.647.6261; Fax: 734.615.8133; E-mail: seanjm@umich.edu. 
1. Altman J, Das GD. Autoradiographic and histological evidence of postnatal hippocampal neurogenesis in rats. J Comp Neurol. 1965;124(3):319-335.

2. Altman J, Das GD. Autoradiographic and histological studies of postnatal neurogenesis. J Comp Neurol. 1966;126(3):337-390.

3. Altman J. Autoradiographic and histological studies of postnatal neurogenesis. IV. Cell proliferation and migration in the anterior forebrain, with special reference to persisting neurogenesis in the olfactory bulb. J Comp Neurol. 1969;137(4):433-458.

4. Luskin MB. Restricted proliferation and migration of postnatally generated neurons derived from the forebrain subventricular zone. Neuron. 1993; 11(1):173-189.

5. Seki T, Arai Y. Highly polysialylated neural cell adhesion molecule (NCAM-H) is expressed by newly generated granule cells in the dentate gyrus of the adult rat. J Neurosci. 1993;13(6):2351-2358.

6. Lois C, Alvarez-Buylla A. Proliferating subventricular zone cells in the adult mammalian forebrain can differentiate into neurons and glia. Proc Natl Acad Sci U S A. 1993;90(5):2074-2077.

7. Kuhn HG, Dickinson-Anson H, Gage FH. Neurogenesis in the dentate gyrus of the adult rat: agerelated decrease of neuronal progenitor proliferation. J NeuroSci. 1996;16(6):2027-2033.

8. Gould E, Tanapat P, McEwen BS, Flugge G, Fuchs E. Proliferation of granule cell precursors in the dentate gyrus of adult monkeys is diminished by stress. PNAS USA. 1998;95(6):3168-3171.

9. Gould E, Reeves AJ, Fallah M, Tanapat P, Gross CG, Fuchs E. Hippocampal neurogenesis in adult old world primates. Proc Natl Acad Sci U S A. 1999; 96(9):5263-5267.

10. Eriksson PS, et al. Neurogenesis in the adult human hippocampus. Nat Med. 1998;4(11):1313-1317.

11. Kornack DR, Rakic P. Cell proliferation without neurogenesis in adult primate neocortex. Science. 2001;294(5549):2127-2130

12. Doetsch F, Caille I, Lim DA, Garcia-Verdugo JM, Alvarez-Buylla A. Subventricular zone astrocytes are neural stem cells in the adult mammalian brain. Cell. 1999;97(6):703-716

13. Palmer TD, Takahashi J, Gage FH. The adult rat hippocampus contains primordial neural stem cells. Mol Cell Neurosci. 1997;8(6):389-404.

14. Reynolds BA, Weiss S. Generation of neurons and astrocytes from isolated cells of the adult mammalian central nervous system. Science. 1992; 255(5052):1707-1710.

15. Lois C, Alvarez-Buylla A. Long-distance neuronal migration in the adult mammalian brain. Science. 1994;264(5162):1145-1148.

16. Rosselli-Austin L, Williams J. Enriched neonatal odor exposure leads to increased numbers of olfactory bulb mitral and granule cells. Brain Res Dev Brain Res. 1990;51(1):135-137.

17. Rochefort C, Gheusi G, Vincent JD, Lledo PM. Enriched odor exposure increases the number of newborn neurons in the adult olfactory bulb and improves odor memory. J Neurosci. 2002; 22(7):2679-2689

18. van Praag H, Kempermann G, Gage FH. Running increases cell proliferation and neurogenesis in the adult mouse dentate gyrus. Nat NeuroSci. 1999;2(3):266-270.

19. Parent JM, Yu TW, Leibowitz RT, Geschwind DH, Sloviter RS, Lowenstein DH. Dentate granule cell neurogenesis is increased by seizures and contributes to aberrant network reorganization in the adult rat hippocampus. J Neurosci. 1997;17(10):3727-3738.

20. Gould E, Tanapat P. Lesion-induced proliferation of neuronal progenitors in the dentate gyrus of the adult rat. NeuroScience. 1997;80(2):427-436.

21. Liu J, Solway K, Messing RO, Sharp FR. Increased neurogenesis in the dentate gyrus after transient global ischemia in gerbils. J Neurosci. 1998; 18(19):7768-7778.

22. Shingo T, et al. Pregnancy-stimulated neurogenesis in the adult female forebrain mediated by prolactin. Science. 2003;299(5603):117-120.

23. Zhang CL, Zou Y, He W, Gage FH, Evans RM. A role for adult TLX-positive neural stem cells in learning and behaviour. Nature. 2008;451(7181):1004-1007.

24. Shors TJ, Miesegaes G, Beylin A, Zhao M, Rydel $\mathrm{T}$, Gould E. Neurogenesis in the adult is involved in the formation of trace memories. Nature. 2001; 410(6826):372-376.

25. Magavi SS, Leavitt BR, Macklis JD. Induction of neurogenesis in the neocortex of adult mice. Nature. 2000;405(6789):951-955.

26. Nakatomi H, et al. Regeneration of hippocampal pyramidal neurons after ischemic brain injury by recruitment of endogenous neural progenitors. Cell. 2002;110(4):429-441.

27. Barnea A, Nottebohm F. Recruitment and replacement of hippocampal neurons in young and adult chickadees: an addition to the theory of hippocampal learning. Proc Natl Acad Sci US A. 1996; 93(2):714-718.

28. Gheusi G, Cremer H, McLean H, Chazal G, Vincent $\mathrm{J}$-D, Lledo P-M. Importance of newly generated neurons in the adult olfactory bulb for odor discrimination. Proc Natl Acad Sci U S A. 2000;97(4):1823-1828.

29. Pardal R, Ortega-Saenz P, Duran R, Lopez-Barneo J. Glia-like stem cells sustain physiologic neurogenesis in the adult mammalian carotid body. Cell. 2007;131(2):364-377

30. Le Douarin NM. The Neural Crest. Cambridge, Massachusetts, USA: Cambridge University Press; 1999.

31. Morrison SJ, White PM, Zock C, Anderson DJ. Prospective identification, isolation by flow cytometry, and in vivo self-renewal of multipotent mammalian neural crest stem cells. Cell. 1999;96(5):737-749.

32. Bixby S, Kruger GM, Mosher JT, Joseph NM, Morrison SJ. Cell-intrinsic differences between stem cells from different regions of the peripheral nervous system regulate the generation of neural diversity. Neuron. 2002;35(4):643-656.

33. Kruger GM, Mosher JT, Bixby S, Joseph N, Iwashita $\mathrm{T}$, Morrison SJ. Neural crest stem cells persist in the adult gut but undergo changes in self-renewal, neuronal subtype potential, and factor responsiveness. Neuron. 2002;35(4):657-669.

34. Molofsky AV, Pardal R, Iwashita T, Park IK, Clarke MF, Morrison SJ. Bmi-1 dependence distinguishes neural stem cell self-renewal from progenitor proliferation. Nature. 2003;425(6961):962-967.

35. Molofsky AV, et al. Increasing p16INK4a expression decreases forebrain progenitors and neurogenesis during ageing. Nature. 2006;443(7110):448-452.

36. Bondurand N, Natarajan D, Thapar N, Atkins C, Pachnis V. Neuron and glia generating progenitors of the mammalian enteric nervous system isolated from foetal and postnatal gut cultures. Development. 2003;130(25):6387-6400.

37. Suarez-Rodriguez R, Belkind-Gerson J. Cultured nestin-positive cells from postnatal mouse small bowel differentiate ex vivo into neurons, glia, and smooth muscle. Stem Cells. 2004;22(7):1373-1385.

38. Rauch U, Hansgen A, Hagl C, Holland-Cunz S, $\mathrm{Schafer} \mathrm{KH}$. Isolation and cultivation of neuronal precursor cells from the developing human enteric nervous system as a tool for cell therapy in dysganglionosis. Int J Colorectal Dis. 2006;21(6):554-559.

39. Metzger M, et al. Expansion and differentiation of neural progenitors derived from the human adult enteric nervous system. Gastroenterology. 2009; 137(6):2063-2073.

40. Kondo T, Raff M. Oligodendrocyte precursor cells reprogrammed to become multipotential CNS stem cells. Science. 2000;289(5485):1754-1757.

41. Gabay L, Lowell S, Rubin LL, Anderson DJ. Deregulation of dorsoventral patterning by FGF confers trilineage differentiation capacity on CNS stem cells in vitro. Neuron. 2003;40(3):485-499.

42. Cracco C, Filogamo G. Mesenteric neurons in the adult rat are responsive to ileal treatment with benzalkonium chloride. Int J Dev Neurosci. 1993; 11(1):49-61.

43. Hanani M, et al. Regeneration of myenteric plexus in the mouse colon after experimental denervation with benzalkonium chloride. J Comp Neurol. 2003;462(3):315-327.

44. Geuna S, Borrione P, Filogamo G. Postnatal histogenesis in the peripheral nervous system. Int J Dev Neurosci. 2002;20(6):475-479.

45. Pham TD, Gershon MD, Rothman TP. Time of origin of neurons in the murine enteric nervous system: sequence in relation to phenotype. J Comp Neurol. 1991;314(4):789-798.

46. Liu MT, Kuan YH, Wang J, Hen R, Gershon MD. 5-HT4 receptor-mediated neuroprotection and neurogenesis in the enteric nervous system of adult mice. J Neurosci. 2009;29(31):9683-9699.

47. Stemple DL, Anderson DJ. Isolation of a stem cell for neurons and glia from the mammalian neural crest. Cell. 1992;71(6):973-985.

48. Molofsky AV, He S, Bydon M, Morrison SJ, Pardal R. Bmi-1 promotes neural stem cell self-renewal and neural development but not mouse growth and survival by repressing the $\mathrm{p} 16 \mathrm{Ink} 4 \mathrm{a}$ and $\mathrm{p} 19$ Arf senescence pathways. Genes Dev. 2005;19(12):1432-1437.

49. Srinivasan S, Stevens M, Wiley JW. Diabetic peripheral neuropathy - evidence for apoptosis and associated mitochondrial dysfunctions. Diabetes. 2000; 49(11):1932-1938.

50. Parr EJ, Sharkey KA. Multiple mechanisms contribute to myenteric plexus ablation induced by benzalkonium chloride in the guinea-pig ileum. Cell Tissue Res. 1997;289(2):253-264.

51. Bush TG, et al. Fulminant jejuno-ileitis following ablation of enteric glia in adult transgenic mice. Cell. 1998;93(2):189-201.

52. Zhuo L, Theis M, Alvarez-Maya I, Brenner M, Willecke K, Messing A. hGFAP-cre transgenic mice for manipulation of glial and neuronal function in vivo. Genesis. 2001;31(2):85-94.

53. Hirrlinger PG, Scheller A, Braun C, Hirrlinger J, Kirchhoff F. Temporal control of gene recombination in astrocytes by transgenic expression of the tamoxifen-inducible DNA recombinase variant CreERT2. Glia. 2006;54(1):11-20.

54. Srinivas $S$, et al. Cre reporter strains produced by targeted insertion of EYFP and ECFP into the ROSA26 locus. BMC Dev Biol. 2001;1:4

55. Laranjeira $C$, et al. Glial cells in the mouse enteric nervous system can undergo neurogenesis in response to injury. J Clin Invest. doi:10.1172/JCI58200. 